\title{
Avaliação da interação universidade -empresa em Santa Catarina por intensidade tecnológica
}

\author{
Silvio Antonio Ferraz Cario $^{1}$ \\ Dannyela da Cunha Lemos ${ }^{2}$ \\ Ariane Simonini ${ }^{3}$
}

Resumo: Dentre as mudanças ocorridas no campo da ciência e da tecnologia nos últimos anos pode-se identificar um estreitamento das relações universidades e setor produtivo, como decorrência de um ambiente institucional que exige cada vez mais uma conexão entre a produção do conhecimento e a sua aplicação prática. Sendo assim, a presente pesquisa tem por objetivo analisar a dinâmica de interação Universidade-Empresa em Santa Catarina (SC), considerando o nível de intensidade tecnológica empresarial. Os resultados apontam que as empresas encomendam pesquisa e participam conjuntamente de pesquisas com empresas voltadas para a inovação, seja na forma de aperfeiçoamento ou de lançamento de produto novo para o mercado. Estas constituem importante instância de transferência de tecnologia, sobretudo pelos conhecimentos gerados nas áreas de engenharia elétrica, engenharia mecânica e ciências da computação. O estudo de caso realizado na Dígitro Tecnologia Ltda., empresa situada na indústria de alta tecnologia, em parceria com a Universidade Federal de Santa Catarina (UFSC) por mais de 15 anos, traduz a virtuosidade da interação meio acadêmico e meio empresarial na construção de processos inovativos, e serve de referência para outras empresas seguirem o mesmo procedimento.

Palavras-chave: Interação universidade-empresa; Intensidade tecnológica; Santa Catarina.

1 Prof. Dr. do Departamento de Ciências Econômicas da Universidade Federal de Santa Catarina - UFSC. E-mail: fecario@yahoo.com.br.

2 Prof a do Departamento de Administração da Universidade Estadual de Santa Catarina - UDESC. Email: lemosda@gmail.com.

3 Economista pela Universidade Federal de Santa Catarina - UFSC. E-mail: ariane_as@hotmail.com. 


\title{
Santa Catarina university/company interaction evaluation by technological intensity
}

\begin{abstract}
Within the changes which have occurred within the science and technology fields in recent years, it is possible to identify a narrowing in relations between universities and the production sector. This is a result of an institutional environment which is increasingly demanding closer contact between knowledge production and its practical application. Therefore, the objective of this study is to analyse the university-company interaction dynamic in Santa Catarina (SC), considering the level of technological business intensity. The results indicate that companies request research and take part together in the research with innovation-oriented companies, whether it is in improvement or launching a new product to the market. These make up an important instance of technology transfer, above all, in the knowledge generated in the electrical and mechanical engineering, and computer science industries. The case study undertaken at Digitro Tecnologia Ltda, a company situated within the area of high technology, in partnership with the Federal University of Santa Catarina, for more than 15 years has reflected the virtuosity of academic and business interaction in the building of innovative processes, and is a reference for other companies to follow the same procedure.
\end{abstract}

Keywords: University-company interaction; Technological intensity; Santa Catarina.

JEL: 031.

Introdução

Atualmente, ganha relevância o estudo dos padrões de interação das produções científicas e tecnológicas, correspondentes, respectivamente, de um lado, às universidades e institutos de pesquisa e, de outro, às empresas, que, por sua vez, desempenham importante papel para a geração dos processos inovativos. Através de processos interativos, o meio acadêmico gera e transfere conhecimentos significativos para o aproveitamento das oportunidades 
tecnológicas que abrem para o meio empresarial. Nestes termos, para uma economia baseada no conhecimento, reconhece-se que a esfera acadêmica é um importante agente do desenvolvimento ao oferecer suporte na construção de capacidades produtivas dinâmicas para as empresas. Dada esta relevância, os governos buscam criar condições para uma maior promoção das relações universidades-empresas e de outros atores institucionais em um ambiente econômico e social mais amplo (Saad; Zawdie, 2011).

No Brasil, um estudo realizado demonstra que as relações universidadeempresa se acham em processo de construção e distantes das experiências existentes nos países desenvolvidos. A aceleração deste processo é indispensável para se aproximar do padrão de processo interativo intenso existente em nível mundial. Sob este quadro, informações do Diretório de Grupos de Pesquisa do Conselho Nacional de Pesquisa Científica e Tecnológica (CNPq) (2006) posicionam o Estado de Santa Catarina (SC) como o $6^{\circ}$ maior número de grupos de pesquisas com interação com empresas do país. Tratase de posição de destaque, visto que o Estado ocupa a $6^{\mathrm{a}}$ posição nacional de produtor de bens e serviços, cuja estrutura compõe-se de empresas que sobressaem em vários setores da economia do país.

Assim, conhecer o padrão de interação universidade-empresa em SC constitui um esforço acadêmico relevante a fim de gerar resultados que venham a contribuir para a formulação de políticas que intensifiquem tais interações. Com este propósito, o presente artigo recorre a resultado de pesquisa de campo efetuada junto às empresas que interagem com universidades em nível estadual, e em alguns momentos comparando com o resultado obtido em nível nacional, segundo a posição empresarial por graus de intensidade tecnológica. Com o intuito de verificar as especificidades desta interação, realiza-se estudo de caso em uma empresa de alta tecnologia - Dígitro Tecnologia Ltda. - cuja trajetória empresarial virtuosa, dentre outros fatores, decorre de longo relacionamento com universidades na geração de conhecimento para suas inovações de produto.

Nesta perspectiva, este artigo compõe-se de 6 seções, sendo que, nesta $1^{\mathrm{a}}$ seção, apresenta-se a introdução; na $2^{\mathrm{a}}$, discutem-se os principais aspectos do referencial teórico analítico sobre interação universidade-empresa; na $3^{\text {a }}$ apontam-se os procedimentos metodológicos que norteiam o estudo; na $4^{\mathrm{a}}$, faz-se a análise dos dados quantitativos coletados por meio da pesquisa com as empresas; na $5^{\mathrm{a}}$, exibe-se o estudo de caso qualitativo da Dígitro; e, por fim, na $6^{\mathrm{a}}$ seção, tem-se a conclusão do estudo. 


\section{Tratamento teórico analítico sobre interação universidade-empresa: aspectos relevantes}

A economia mundial, nos últimos tempos, passa por intensa transformação sob o signo de um paradigma técnico - produtivo, que elege o conhecimento como instrumento essencial para o desenvolvimento de processos inovativos. Deste modo, o desenvolvimento do conhecimento e a capacidade de busca por inovação se tornam referências para os países, tanto os desenvolvidos como os em desenvolvimento, empreenderem esforços voltados à promoção de tais requerimentos. Considerando que a inovação é um processo social e sistêmico, envolvendo diferentes atores, tem-se observado ações direcionadas à produção e difusão do conhecimento com propósitos inovativos. Assim, as interações de universidades, empresas, governos, entre outros, têm sido marco de referência nos estudos sobre processo inovativo, e dada a existência de diferentes arranjos, decorrem distintos enfoques analíticos conceituais.

Nesta perspectiva, destaca-se o trabalho de Sábato e Botana (1968), que introduziu na América Latina as ideias seminais de uma estratégia de inserção da ciência e tecnologia para o processo de desenvolvimento dos países, por meio da articulação de três atores fundamentais: o governo, as universidades e as empresas. Cada um destes atores pode ser ilustrado por meio de um vértice que dá origem ao "Triângulo de Sábato", onde se estabelecem relações que podem acontecer dentro de cada vértice (intrarrelações), relações que ocorrem entre os três vértices do triângulo (inter-relações) e ainda as relações entre os três atores do triângulo e o meio externo (extrarrelações). Desta forma, inovação é um produto deste sistema de relações, ressaltando-se o caráter fundamental das inter-relações estrutura científico-tecnológica, representada pelas universidades, e estrutura produtiva, respectivamente.

Há que se ressaltar também as proposições teóricas decorrentes do modelo da "hélice tripla", de Etzkowitz e Leydesdorff (2000), que referencia as relações entre três esferas: a universidade, a empresa e o governo em um processo evolutivo. Segundo os autores, a concepção de "hélice tripla I" o EstadoNação engloba as universidades e empresas e dirige as relações entre eles. Já a concepção de "hélice tripla II" consiste na separação institucional das esferas com fronteiras bem demarcadas e relações circunscritas entre elas. Por fim, na proposição de "hélice tripla III", uma sobreposição das esferas propicia a geração de uma estrutura de conhecimento, o que permite o surgimento de organizações híbridas. Nesta última concepção, cada esfera assume, além de suas tradicionais funções, o papel das outras, o que pode tomar a forma de diferentes combinações, tais como: spin-off, iniciativas tri-laterais, alianças estratégicas entre diferentes tipos de empresas, laboratórios governamentais ou grupos de pesquisa acadêmicos. Tais combinações devem ser encorajadas, mas não controladas pelo Estado (Leydesdorff; Etzkowitz, 1998; Etzkowitz; 
Leydesdorff, 2000).

Do ponto de vista da universidade, configura-se uma "segunda revolução acadêmica”, onde esta incorpora como parte de sua missão, o desenvolvimento social e econômico. Desta missão, firma-se um novo contrato social entre a universidade e a sociedade, que impõe à primeira uma participação mais ativa no processo de desenvolvimento, o que se caracteriza como sua "terceira missão". Tal concepção traz em seu bojo o conceito de "universidade empreendedora", que integra o desenvolvimento econômico dentro da universidade como mais uma função, além do tradicional ensino e pesquisa (Etzkowitz; Leydesdorff, 2000; Saad; Zawdie, 2011).

Outra abordagem predominante do tema interação U-E é baseada nos estudos de Schumpeter (1982), que fornecem uma visão de desenvolvimento a partir da inovação e introduzem ideias fundamentais para o entendimento de uma dinâmica econômica, cujas relações entre pessoas e organizações representam papel decisivo para seu sucesso. Como decorrência, a literatura neo-schumpeteriana que trata de Sistema Nacional de Inovação (SNI) (Freeman,1995; Nelson,1993; Lundvall,1992) é uma referência relevante no tratamento da interação U-E, pois ressalta o papel dos processos de aprendizado como componentes da difusão de inovações. A escola neoschumpeteriana enfatiza a importância de esforços explícitos para gerar novos conhecimentos, difundindo-os no sistema produtivo, de forma a gerar inovações e incrementar o desenvolvimento (Lastres; Ferraz, 1999).

O SNI compreende um arranjo institucional envolvendo múltiplos participantes, tais como as empresas e suas redes de cooperação e interação; as universidades e institutos de pesquisa; as instituições de ensino; sistema financeiro; leis; mecanismos mercantis e não-mercantis de seleção; governos; e mecanismos e instituições de coordenação. Tal arranjo articula riqueza econômica com competências tecnológicas fundamentais, motivo pelo qual ganham relevância as instituições e os mecanismos de cooperação (Bernardes; Albuquerque, 2003; Fernandes et al., 2010).

Destaca-se, neste arranjo, o papel tanto das universidades como das empresas, identificando-se, no relacionamento dinâmico entre estes dois componentes chaves do SNI, uma co-evolução de fatores como as capacidades de pesquisa das universidades e institutos de pesquisa, de um lado, e a capacidade de absorção das firmas, de outro (Rapini et al., 2009). Desta maneira, o estudo dos sistemas de ciência e tecnologia (C\&T) dá lugar às análises mais abrangentes dos SNIs, fazendo com que as instituições dedicadas à produção científica, como as universidades, integrem as instâncias responsáveis pela inovação (Brisolla, 1998).

O conceito de SNI é uma referência significativa para a discussão da dinâmica tecnológica em vários países. Tal abordagem leva em consideração 
a importância da interação das instituições que fazem parte do processo inovativo, uma vez que esta interação dos diferentes atores da economia influencia a criação e a difusão de novas tecnologias, que, por sua vez, impulsionam o progresso tecnológico de um país (Righi, 2009). As interações se tornam estratégicas porque os conhecimentos para a inovação são gerados em outras organizações com as quais se torna relevante estabelecer canais de comunicação, incluindo as produtoras do conhecimento, como fontes indispensáveis ao processo inovativo (Maculan, 2005).

Os relacionamentos requeridos para trocar e combinar conhecimentos e experiência entre os atores são um fator crucial de diferenciação dos SNIs de países desenvolvidos e não desenvolvidos (Fernandes et al., 2010). Nos países menos desenvolvidos, este tema recentemente tem recebido mais atenção, fomentando, sobretudo, estudos na América Latina (Stuz, 2000; Dutrénit; Arza, 2010). Justamente, nestes países, a interação ciência e tecnologia mostra-se fundamental para o processo de catching-up, o que significa a adoção de políticas públicas que promovam o suporte e o fortalecimento das instituições científicas, implicando profundo compromisso com o progresso social, especialmente com aumento do nível educacional da população (Bernanrdes; Albuquerque, 2003).

Neste contexto, as universidades desempenham, além de suas funções, um duplo papel na sua interação com as empresas: elas atuam em substituição e complemento ao sistema de pesquisa e desenvolvimento (P\&D) destas últimas (Rapini et al., 2009). As instituições acadêmicas são importantes para empresas e governos, uma vez que produzem soluções para problemas locais e demandas emergentes. Elas atuam como "antenas" para as empresas locais terem acesso ao conhecimento e à tecnologia, além de ajudá-las a construir internamente competências de pesquisa que ainda não dispõem (Fernandes et al., 2010). A interação universidade-empresa revela grande potencial para alavancar o crescimento econômico, num plano nacional de desenvolvimento, dentro de uma ótica que priorize os processos inovativos e defina as funções de cada uma das instituições envolvidas para atendimento às demandas nacionais (Brisolla, 1998).

Na visão de Segatto-Mendes e Sbragia (2002), a literatura aborda diversas classificações dos possíveis tipos de relações estabelecidas entre as universidades e as empresas para a pesquisa conjunta de tecnologia, mas não existe consenso ou padrão rígido para os tipos de relações que devem ser feitas. Apoiados na classificação de Bonaccorsi \& Piccaluga (1994), os autores citam os seguintes instrumentos, como forma de cooperação entre as universidades e empresas: relações pessoais informais (consultorias individuais, publicações, trocas informais, workshops); relações pessoais formais (trocas de pessoal, estudantes internos); terceira parte (associações industriais, institutos de pesquisa aplicada...); acordos formais com alvo definido (pesquisas contratadas, treinamento, projetos de pesquisa cooperativa); sem alvo definido 
(patrocinadores de pesquisa); criação de estruturas focalizadas (contratos de associação, consórcios de pesquisa, centro de incubação-inovação).

Em complemento, Rapini et al. (2009) mencionam que a participação das universidades na dinâmica empresarial tem aumentado e que se podem observar as seguintes contribuições para o processo inovativo das firmas: (i) fornecimento, por parte da pesquisa acadêmica, de compreensão e técnicas que a indústria pode empregar para uma variedade de propósitos; (ii) parceria para o desenvolvimento de pesquisas mais flexíveis, não restritas às áreas de treinamento e desenvolvimento $(\mathrm{P} \& \mathrm{D})$ das empresas, ou uma compensação da ausência desta área, no caso das pequenas empresas; (iii) formação e treinamento de profissionais capazes de lidar com problemas associados ao processo inovativo; (iv) criação de novos instrumentos e técnicas científicas; e (v) criação de firmas nascentes (spin-offs) por pessoal acadêmico.

Seguem-se, também, as observações de Segatto-Mendes e Sbraggia (2002) acerca das vantagens que o processo interativo proporciona, tanto para universidades, como para empresas e governo. Para as universidades, a interação é uma possibilidade de captar recursos financeiros, físicos e humanos adicionais e complementares para o desenvolvimento de pesquisa, contribuindo, assim, para manter a pesquisa de vanguarda no ambiente universitário, bem como, oferecendo um ensino vinculado aos avanços tecnológicos em contribuição para o desenvolvimento econômico do país. Para as empresas, a interação possibilita o desenvolvimento de tecnologia com menores recursos financeiros, temporalidade e risco; ter acesso aos laboratórios de pesquisa e utilizar os recursos humanos qualificados; e contar com sistemática de atualização tecnológica de forma constante. Em relação ao governo, a interação universidade-empresa propicia, com menor nível de investimento na infraestrutura e capacidade instalada de $\mathrm{P} \& \mathrm{D}$, fomentar e obter melhores resultados no desenvolvimento de programas que envolvam várias áreas - econômica, social, tecnológica - contribuindo, desta forma, para a difusão na sociedade em geral.

Reconhecida a importância da interação universidade-empresa na construção de condições para o desenvolvimento, cumpre superar os entraves que limitam a expansão desta relação. Cabe à universidade aprender a interagir com as empresas, entender seus problemas e buscar ajuda na solução ou na proposição de novas tecnologias. Há que criar condições para a superação de problemas tais como: o grau de incerteza dos projetos, a localização geográfica das instituições, apoio governamental, sistema de distribuição de incentivos financeiros a universidades e a diferença do nível de conhecimento entre as universidades e empresas (Segatto-Mendes; Sbragia, 2002). Assim, as empresas precisam desenvolver capacidade para absorver as tecnologias, internalizar atividades de P\&D, e principalmente, aprender a inovar (Righi, 2009). 


\section{Procedimentos metodológicos}

Em Santa Catarina (SC), foram identificadas, no Diretório dos Grupos de Pesquisa do $\mathrm{CNPq}$ (DGP/CNPq) em 2006, 88 empresas catarinenses, das quais 29 responderam ao questionário de pesquisa (32,9\%). Deste modo, utilizou-se uma amostra não-probabilística, que pode ser classificada como uma amostra por acessibilidade. As empresas que participaram do estudo foram citadas por grupos de pesquisa cadastrados no DGP/CNPq e participaram do Censo do DGP/CNPq de 2006.

Em relação às grandes áreas do conhecimento, a maior representatividade em SC foram as Engenharias, com 75,9\% da amostra, seguindo o padrão de representatividade nacional. A maior concentração de empresas que responderam ao questionário está localizada na região da Grande Florianópolis, com 18 das 29 empresas, ou seja, 62,1\%. Os demais municípios catarinenses onde estão localizadas as empresas que responderam à pesquisa são: Joinville (5), Gaspar (2), São Francisco do Sul (1), Indaial (1), Jaraguá do Sul (1) e Faxinal dos Guedes (1). Tal fato decorre de parte considerável da estrutura produtiva estar localizada na faixa litorânea do Estado, assim como as principais Universidades, quais sejam a Universidade Federal de Santa Catarina (UFSC), Universidade do Estado de Santa Catarina (UDESC), Fundação Universidade da Região de Blumenau (FURB), Fundação Universidade da Região de Joinville (UNIVILLE), Universidade do Extremo Sul Catarinense (UNESC), Universidade do Vale do Itajaí (UNIVALI) e Universidade do Sul de Santa Catarina (UNISUL).

$\mathrm{Na}$ análise, foi considerado o ramo de atividade industrial, tomando por base as quatro categorias de intensidade tecnológica em que a Organização para a Cooperação e o Desenvolvimento Econômico (OCDE) segmenta: indústria de alta tecnologia, indústria de média-alta tecnologia, indústria de média-baixa tecnologia e indústria de baixa tecnologia, conforme Tabela $1^{4}$.

No que diz respeito ao ramo de atividade, a base de dados é composta majoritariamente por empresas da indústria de transformação (62,8\% das 325) no Brasil. $\mathrm{Na}$ atividade industrial, incluem-se também as firmas do setor de extração mineral $(3,4 \%)$, totalizando nesta categoria $66,2 \%$ da amostra no Brasil. A pesquisa cobriu também atividades do setor de serviços, representando 33,8\% da amostra. Em Santa Catarina, a indústria de transformação representou $48,3 \%$ das 29 empresas e $51,7 \%$ no setor de serviços. Na amostra de SC, não houve ocorrência de empresas do setor de agropecuária e silvicultura e de indústrias extrativas. Em comparação, os números mostram maior equilíbrio entre os setores, indústria e serviços, analisados em SC (48,3\% e 51,7\%) em relação ao Brasil (66,2\% e 33,8\%). 
Informa-se que várias empresas que responderam o questionário figuram entre as principais nos setores que atuam, tais como: no segmento industrial de alta intensidade tecnológica, as empresas de software e telecomunicações Dígitro Tecnologia Ltda e a Intelbras S.A.; na indústria de média-alta tecnologia, estão as empresas de motores elétricos e compressores, Weg Industrias S.A., Empresa Brasileira de Compressores S.A. - Embraco - atual Whirlpoll; na indústria de média-baixa tecnologia, a empresa de plásticos residenciais e industriais, Tigre S.A. - Tubos e Conexões; e na indústria de média-baixa tecnologia, a empresa de alimentos, Bungue Alimentos S.A. Nos serviços, tem-se engenharia e P\&D, a Empresa de Pesquisa Agropecuária e Extensão rural de SC - EPAGRI; na informação e comunicação, o Centro de Informática e Automação do Estado de SC - CIASC; nos serviços de utilidade pública energia -, a Eletrosul Centrais Elétricas S. A. e Tractebel Energia S.A.

Com o propósito de fazer a avaliação específica da interação U-E, selecionou-se uma empresa situada no segmento industrial de alta tecnologia, que é a Dígitro Tecnologia Ltda. Tal empresa se notabiliza por ser uma das maiores provedoras de soluções no segmento de telecomunicações no Brasil, desenvolvendo seus processos inovativos em interação principalmente com a Universidade Federal de Santa Catarina. Esta interação vem ocorrendo há mais de 15 anos e tem resultado numa ampla transferência de conhecimentos que dão origem regularmente a novos produtos. Para a elaboração do estudo de caso, foram utilizadas, além do questionário da pesquisa respondido pela empresa, dados qualitativos extraídos por meio de entrevista semiestruturada realizada com o responsável pela coordenação de projetos junto às universidades e também com o responsável pela gestão da prestação de contas destes projetos. As entrevistas foram gravadas e transcritas para posterior análise a partir da fala dos entrevistados que é apresentada ao longo do texto. A escolha por uma empresa pertencente ao segmento de alta intensidade tecnológica foi intencional, considerando-se ser um setor intensivo em conhecimento e baseado em ciência, no qual se acredita haver maiores condições para a interação U-E.

\section{Dinâmica da interação U-E em Santa Catarina em relação ao Brasil sob a ótica da intensidade tecnológica}

As empresas realizam inovações de processo e produto com perspectiva de aumentarem as condições competitivas no mercado. As inovações de processo decorrem de ações voltadas às modificações técnicas de produção, como a introdução de novas máquinas e equipamentos e a utilização de nova matéria-prima, ao passo que, as inovações de produto pautam por mudanças 
de conteúdo e de desenho, por exemplo. No tocante às informações fornecidas pelas empresas pesquisadas sobre tais inovações, verifica-se, conforme Tabela 2, que as empresas que não apresentam inovação em produto novo representam apenas $8,6 \%$ no Brasil e $6,9 \%$ em SC; e em processo, $7,7 \%$ e $3,5 \%$, respectivamente, evidenciando que a grande maioria das empresas realiza inovações em suas atividades, sobretudo as pesquisadas em SC. Destaque para o aperfeiçoamento em produto existente, $62,9 \%$ no Brasil e $72,4 \%$ em SC; e em processo, $68,4 \%$ e $89,7 \%$, respectivamente. Tal fato sinaliza uma característica do processo produtivo nacional e estadual pautada em maior proporção dos esforços inovativos por mudanças incrementais. As referidas inovações decorrem de mudanças em pequena dimensão da estrutura existente, em face de estas se basearem no conhecimento e na experiência acumulados e por gerar maior segurança nos processos decisórios frente à incerteza dos resultados que a inovação provoca.

Quando ao novo produto e ao novo processo para a empresa, identificam-se, respectivamente, os seguintes percentuais de inovação, 47,6\% no Brasil e $62,1 \%$ em SC e $42,9 \%$ no Brasil e $58,6 \%$ em SC, para cada conjunto de empresas da amostra que responderam o questionário. Ressalta-se, também, o percentual significativo de inovação em novo produto para o país, com 41,1\% no Brasil e 58,6\% em SC. Nestes termos, ainda que em menor proporção que os aperfeiçoamentos de produtos e processos, observam-se esforços inovativos em introduzir algo até então inexistente no mercado. Este requerimento expressa caráter mais desafiador do processo inovativo em relação à modificação de algo que já existe. Registra-se, também, que, das empresas que responderam o questionário em cada grupo, BR e SC, os percentuais apresentados, seja em aperfeiçoamento, seja em produto e processos novos, expressam maior proporção de incidência em SC do que no BR, demonstração de maior esforço de inovação das empresas catarinenses em relação às nacionais.

No tocante às inovações de produto e processo por intensidade tecnológica, observa-se que as empresas inseridas nas indústrias de média-alta e médiabaixa tecnologia são as que mais desenvolvem inovações em aperfeiçoamentos e em novos produtos e processos, no Brasil e em SC, entre as empresas que responderam os questionários. No âmbito do segmento de serviços, os segmentos de Engenharia e P\&D, Informações e Comunicações e Serviços de Utilidade Pública são os que ditam as inovações, nos níveis nacional e estadual.

O investimento em P\&D significa processo de busca por inovação de forma organizada e persistente. Neste sentido, pessoas com capacitação técnica e volume de recursos são envolvidos diretamente neste processo. Por consequência, as possibilidades de surgimento de inovação são maiores. Assim sendo, ao considerar o percentual de investimento em P\&D em relação ao faturamento das empresas, identificam-se informações relevantes para verificar os esforços realizados com processos de inovação. 
Verifica-se, na Tabela 3, que número próximo de $1 / 3$ das empresas que responderam o questionário no Brasil $(30,5 \%)$ e em SC $(27,6 \%)$ declara investir até $0,5 \%$ do faturamento em $\mathrm{P} \& \mathrm{D}$, em especial, grande parte das indústrias de média-baixa tecnologia, indústria de baixa tecnologia, indústria extrativa, serviço de utilidade pública e outros serviços. Este percentual encontra-se em sintonia com os resultados de estudos nacionais que apontam investimento médio de menos de $1 \%$ do faturamento em P\&D. Seguem, também, os resultados exibidos em estudos da Pesquisa Industrial de Inovação Tecnológica PINTEC - do IBGE que revelam que em torno de $1 / 3$ das empresas brasileiras realizam processos inovativos.

Por outro lado, acerca das empresas entrevistadas que realizam elevado percentual de gastos em P\&D, nota-se que $24,1 \%$ das empresas de SC apresentam investimento em $\mathrm{P} \& \mathrm{D}$ de $10,1 \%$ a $20 \%$ em relação ao faturamento, número bastante superior ao investimento nacional cujo registro é de $5,8 \%$, nesta categoria, com destaque para as indústrias de alta e média-alta tecnologia. $\mathrm{O}$ predomínio de investimento em $\mathrm{P} \& \mathrm{D}$ nas indústrias de alta tecnologia está na faixa de 2,1\% a $5 \%$ no Brasil. Em SC, as duas empresas da indústria de alta tecnologia declaram fazer investimento em P\&D de 2,1\% a $5 \%$ e de $10,1 \%$ a $20 \%$. Tais números demonstram que os maiores percentuais em $\mathrm{P} \& \mathrm{D}$ concentram-se em segmentos industriais de maior conteúdo tecnológico. A estrutura destas indústrias exige investimentos voltados em aproveitar as oportunidades tecnológicas, sobretudo, aquelas baseadas em ciência e com grande penetrabilidade setorial, como a eletrônica, a informática e a química.

As fontes de informação alimentam os processos inovativos, pois auxiliam na construção dos caminhos de busca a serem seguidos. As referidas fontes servem para guiar, sugerir e servir de material para iniciar e concluir os projetos. Nesta perspectiva, as empresas recorrem a fontes tanto internas como externas. O cliente é considerado a fonte primordial para a geração de novos projetos, segundo as empresas selecionadas, sendo destaque para $34,5 \%$ no Brasil e 41,4\% em SC, para as situadas na indústria de média-alta tecnologia, nos serviços de informação e comunicação, de acordo com a Tabela 4. Tal ocorrência aponta a importância das sugestões dos consumidores sobre novas tendências no mercado. Em pauta, o processo de aprendizagem tecnológica ditada pelo uso do produto. Clientes utilizam os produtos e apontam problemas, sugerem tendências e as empresas consideram como elevada relevância em seus esforços de promoção de inovação. Por sua vez, a linha de produção da própria empresa é responsável pela principal fonte de informação para concluir projetos com $24,0 \%$ no Brasil e $17,2 \%$ em SC, com destaque para a indústria de média-baixa tecnologia e outros serviços, como pode ser visto na Tabela 5 . Neste aspecto, o cotidiano das operações possibilita, através de tentativas e erros, definir a trajetória do progresso percorrido pelas mudanças técnicas. Ênfase para o processo de aprendizagem tecnológica pelo fazer, cuja experiência, habilidade e destreza do trabalhador condicionam 
os esforços voltados a fazer mudanças em direção do novo. Cada uma dessas fontes assume a segunda posição em importância relativa no âmbito em que a outra é privilegiada.

A Universidade situa-se em terceiro lugar em ambas, com parcelas bem parecidas, $12,9 \%$ no Brasil e 13,8\% em SC, para sugerir novos projetos, e $13,2 \%$ no Brasil e $17,2 \%$ em SC, para a conclusão de projetos, com realce para as indústrias de média-baixa tecnologia e serviço de utilidade pública. Perante os números de fontes de informação apresentados, a Universidade e os Institutos de Pesquisas ocupam posições relevantes. Destacam-se os processos de aprendizagem por interação, onde a troca de informação e a transferência de conhecimento são primordiais para o desenvolvimento de processos inovativos.

Considerando a Universidade como uma das principais fontes de informação para a atividade inovativa, as empresas atribuem graus de importância para um conjunto de itens, conforme disposição na Tabelas 6a e 6b. Chama a atenção o fato de que as empresas em todos os agrupamentos de atividade tendem a atribuir pouca importância à maioria dos mecanismos costumeiros enfatizados pelos gestores de tecnologia, tais como, incubadoras, parques científicos ou tecnológicos e spin-offs. Pinho (2011) aponta uma possível hipótese para explicar esse resultado. Os efeitos dos mecanismos de transferência de tecnologia tendem a ser poderosos, mas concentrados num número pequeno de empresas muito favorecidas.

Pesquisa conjunta, publicações, contratação de pessoal, conferências, troca informal de informações e pesquisa encomendada são todos meios de interação que, na média das empresas entrevistadas, atingem o grau de moderadamente importante em quase todos os agrupamentos setoriais e superam por boa margem aqueles instrumentos usuais de transferência de tecnologia.

Para os números apresentados, constata-se que, tanto para o Brasil como para SC, maior atribuição de importância é dada à pesquisa encomendada às Universidades e à pesquisa realizada em conjunto com as Universidades. Em destaque para $\mathrm{SC}$, as empresas da indústria de alta tecnologia atribuem valoração máxima, 4,o, considerada muito importante, seguida de moderadamente importante, 3,0, pelas empresas do segmento industrial de média-alta tecnologia. Da mesma forma, dão importância para outras funções da Universidade, como a formação de pessoal com graduação e pós-graduação.

No âmbito dos segmentos que compõem o setor de serviços, observa-se atribuição à importância das fontes de informação com Universidades para empresas situadas nos segmentos de Informação e Comunicação e Serviços de Utilidade Pública. Alguns itens alcançam valoração máxima, 4,o, como a participação em redes que envolvem a Universidade para Informação e Comunicação, e próximo deste número atribuído, 3,8 , em pesquisa realizada em 
conjunto com Universidade para o segmento de Serviços de Utilidade Pública em SC. Em tais segmentos, o marco institucional existente - lei da inovação e legislação de órgão regulador - exige contrapartida para a obtenção de benefícios fiscais, como o cumprimento de determinada obrigatoriedade de gastos em $\mathrm{P} \& \mathrm{D}$, conduzindo, assim, à maior aproximação com Universidades para a realização de projetos inovativos.

Outra importante análise refere-se às áreas de conhecimento que se destacam como foco de interesse para as atividades inovativas. Segundo a Tabelas $7 \mathrm{a}$ e 7b, são referências as áreas das ciências da computação e as engenharias, valorizadas tanto pelas empresas entrevistadas em SC como no Brasil. Para as empresas das indústrias de alta e média-alta tecnologias em SC contribuem de forma significativa para os processos inovativos, os conhecimentos provenientes das áreas de computação e engenharia elétrica, e em menor consideração, a engenharia mecânica. Da mesma forma, a ciência da computação e as engenharias se destacam como referências de áreas do conhecimento para a inovação nos segmentos do setor de serviços, em particular nos de Utilidade Pública e Informação e Comunicação.

Os resultados até então apresentados são corroborados pelas respostas das empresas, informando a principal razão para a ocorrência de colaboração entre U-E, conforme Tabelas 8a e 8b. As respostam apontam a existência de várias razões para a ocorrência de processo interativo das esferas acadêmica e empresarial, cujos números expressam mais significância nas respostas das empresas de SC do que nas processadas pela amostra de empresas do Brasil. Em pauta, destacam como referência contratar pesquisas complementares, transferência de tecnologia, pesquisa que a empresa não pode realizar, consultoria com pesquisador professor e testes para produtos e processos para os níveis de valoração moderadamente importante e muito importante. Para as empresas situadas na indústria de alta tecnologia, a maior valoração de importância coube a contratar pesquisas complementares, dado que possuem equipe de profissionais que se responsabilizam, também, por esta tarefa no interior das empresas. Ao passo que, para as empresas de média-alta tecnologia, ênfase à informação sobre tendência de $\mathrm{P} \& \mathrm{D}$ nas atividades que atuam, valendo-se do conhecimento atualizado dos professores pesquisadores, em suas áreas de concentração de estudos e pesquisas. Tais itens são considerados, também, relevantes para os segmentos do setor de serviços: Informação e Comunicação e Serviços de Utilidade Pública.

Enquanto, que para as empresas catarinenses, a principal razão para a colaboração com a universidade refere-se à transferência de tecnologia, para as empresas brasileiras, situa-se em utilizar a infraestrutura para pesquisa e testes para produtos e processos. Em relação à SC, significa relevância dada à compra de pacote tecnológico desenvolvido na universidade e adequado pela empresa. No tocante ao Brasil, empresas recorrem à universidade para fazer uso de sua pesquisa e dos serviços tecnológicos disponíveis. Considerando 
o destaque por intensidade tecnológica, verifica-se que em SC, as empresas da indústria de alta tecnologia atribuem à contratação de pesquisas complementares um quesito muito importante $(4,0)$ para realizar colaboração com a Universidade. Com o mesmo propósito, no setor de serviços, as empresas situadas no segmento de informação e comunicação atribuem como muito relevante a contratação de consultoria com pesquisadores/professores $(4,0)$.

Analisando-se os agentes responsáveis pela iniciativa de relacionamento com a Universidade agrupados nas categorias empresa, grupo de pesquisa, empresa/ grupo de pesquisa (compartilhada) e mecanismos institucionais (institucional), se destacam, a partir de informações coletadas junto às respostas das empresas, que, em SC, 33,3\% dos relacionamentos entre as empresas e as universidades são estabelecidos por iniciativa das empresas e outros 33,3\% por iniciativa compartilhada. No Brasil, 42,7\% dos relacionamentos são estabelecidos por iniciativa das empresas e $32,9 \%$ de forma compartilhada. Tais resultados mostram interesses iniciais mútuos entre as partes, sem a dominância de um ou de outro. Quanto aos resultados alcançados pela interação realizada com as universidades, empresas julgam que esta tem sido bem-sucedida, sendo apreciada, desta forma por $1 / 2$ das empresas do Brasil entrevistadas e por pouco mais de $1 / 4$ das empresas de SC.

\section{Estudo de caso da Dígitro}

\subsection{A empresa e o contexto tecnológico}

A Dígitro Tecnologia Ltda., fundada em 1977, é uma das maiores empresas provedoras de soluções no segmento de telecomunicações do Brasil, reconhecida por sua capacidade de criar e desenvolver produtos inovadores. A empresa caracteriza-se como uma grande organização de capital privado nacional voltada para a fabricação de equipamentos de comunicação, e é classificada como uma empresa de alta tecnologia, que desde 1983, quando desenvolveu a primeira plataforma para o serviço teledespertador automático para operadoras de telefonia, vem incorporando ao seu portfólio vários produtos que traduzem soluções em tecnologia.

A empresa é sediada em Florianópolis-SC, com filiais nas principais cidades do país, tais como: Porto Alegre/RS, Curitiba/PR, São Paulo/SP, Ribeirão Preto/SP, Brasília/DF, Rio de Janeiro/RJ, Fortaleza/CE e Recife/PE, conta com aproximadamente 600 funcionários, atende a cerca de 2.500 clientes, 
em um parque instalado de 6.200 plataformas servido por 65 representantes comerciais em todo o país e 95 representantes técnicos no Brasil e em países da América Latina e África. Dentre os produtos e serviços oferecidos pela empresa, ressaltam-se soluções de inteligência em comunicação de dados, voz e imagem; tecnologias Dígitro de informação e telecomunicações e o Dígitro Service, que oferece serviços de outsourcing no gerenciamento de estruturas de tecnologia de informação e conhecimento, como detalhado na Tabela 9.

Ênfase para o alto grau de qualificação do quadro de pessoal, cuja formação de cerca de 50\% dos funcionários é de ensino superior completo ou de pósgraduação. Destaca-se ainda que aproximadamente $25 \%$ dos funcionários possuem nível superior incompleto. A empresa também investe regularmente em treinamento de pessoas, além de absorver em seu quadro de pessoal formandos de cursos universitários e técnicos. Como resultado dos processos de treinamento e aprendizagem, a empresa salienta como importante o melhor uso de técnicas produtivas, equipamentos e insumos; capacitação para modificar produtos e processos e desenvolver novos produtos e processos; ampliação do conhecimento sobre as características de seus mercados de atuação e ainda melhor capacitação administrativa.

\subsection{Histórico da interação}

A Dígitro iniciou o processo de interação com universidades em 1996, mais precisamente com a Universidade Federal de Santa Catarina (UFSC), com o Laboratório de Circuitos e Processamento de Sinais (LINSE), que é uma unidade de pesquisa do Departamento de Engenharia Elétrica. Em 2009, foi também firmada parceria com o Laboratório de Integração de Software e Hardware, ligado ao Departamento de Ciências da Computação, da mesma Universidade. A empresa mantém também desde 2003 parceria com o Instituto Atlântico (PE) e com a Universidade Federal do Ceará (UFC).

Desta forma, a Dígitro mantém relação com as universidades e institutos de pesquisa há cerca de 15 anos e considera que até o momento a colaboração tem sido um sucesso para atingir seus objetivos. Neste sentido, a empresa avalia que o ensino é a função da universidade mais importante para a empresa, seguida da pesquisa e do empreendedorismo.

A iniciativa para a interação partiu de funcionários da Dígitro que haviam sido alunos da UFSC, conforme comentado: “[...] muitas pessoas que hoje são gerentes, com cargos de alta confiança, foram alunos destes laboratórios, então existe uma grande parceria de conhecimento entre a empresa Dígitro e estes laboratórios." Além disso, a empresa também se beneficia da Lei da 
Informática, o que exige que ela invista em Institutos de Pesquisa, cuja seleção deu-se fundamentalmente em função dos laços firmados com os ex-alunos "[...] a Dígitro optou por selecionar o LINSE como o instituto que receberia esta verba da Lei de Informática [...] justamente pela questão de funcionários ou alunos serem oriundos lá deste laboratório”.

O atual gerente de desenvolvimento (Soluções em Tecnologia e Embarcados) da Dígitro, assim como outros funcionários, ingressaram na empresa como estagiários do curso de engenharia elétrica "[...] todos eles começaram como estagiários de engenharia e, conforme o tempo, foram agregando conhecimento nos parceiros e agora são gerentes. [...] os gerentes, eles têm como se fosse um nível de diretor, digamos assim, o grau de importância deles dentro da empresa”.

Sobre os fatores que levaram a empresa a participar de projetos cooperativos com grupos de pesquisa, ela diz que "[...] se existem tecnologias que podem ser desenvolvidas fora, se tem grupos com capacidade e competência para desenvolver, desonera um pouco também a carga dos nossos colaboradores; eles também agregam o conhecimento deles, que depois é transmitido para a empresa." Sendo assim, a cooperação é estimulada como forma de aquisição de novas competências e busca de tecnologias que possam ser mais bem desenvolvidas externamente para posterior incorporação ao portfólio de produtos da empresa.

Então, o processo de interação com universidades e institutos de pesquisa na Dígitro tem basicamente como objetivo, captar novas tecnologias "[...] a gente atinge nosso objetivo que é desonerar a nossa equipe, é desenvolver novos produtos, novas tecnologias, é agregar também mais conhecimento para os nossos produtos [...]". Outro objetivo é a captação de recursos humanos “[...] a gente já contratou, desde o começo, em torno de quase 10 funcionários que vieram destes laboratórios, destas parcerias que a gente acabou desenvolvendo. $\mathrm{E}$ muitos funcionários são indicados pelos próprios professores dos laboratórios que acaba tendo a interação."

Ao longo do tempo, a parceria vem sendo desenvolvida como um processo contínuo, mas são realizados projetos específicos, com datas de início e término. Embora a empresa não possua uma cronologia detalhada destes projetos, todos eles são monitorados, até por exigência da própria Lei de Informática da qual a empresa se beneficia "[...] a gente precisa informar quando que começou, quanto tempo vai levar, em que fase está o desenvolvimento, isso a gente acaba detalhando."

Outro aspecto a considerar é que há um período de tempo entre o desenvolvimento de uma tecnologia junto à Universidade e a sua completa incorporação dentro da infraestrutura Dígitro, o que depende da programação interna da equipe e do próprio estágio de maturação do produto. “[...] eu posso ter um 
produto pronto para o laboratório em 2005 que eu só vou agregar, na Dígitro, dois ou três anos depois, ou um ano depois, depende da demanda para este novo produto." Assim, muitas tecnologias desenvolvidas como resultantes da interação vão sendo aperfeiçoadas ao longo do tempo com incrementos inovativos até darem origem a novos produtos.

\subsection{A importância das atividades inovativas}

Sobre as atividades inovativas, a Dígitro empreende esforços tanto na introdução de novos produtos como de novos processos. Com relação aos novos produtos, trabalha no aperfeiçoamento de produtos já existentes no mercado e também no desenvolvimento de produtos novos para a empresa, para o país e para o mundo, dentre os quais, pode se destacar os dispositivos de VoIP, que representam uma avançada tecnologia de comunicação com a praticidade de um aparelho telefônico a custos reduzidos. No que tange às inovações de processos, a Dígitro também procura aperfeiçoar processos já existentes e introduzir processos novos para a empresa, dentre os quais, se pode citar a introdução de avançadas técnicas de gestão e métodos de gerenciamento visando atender as normas de certificação, além da implementação de mudanças na estrutura organizacional e conceitos e práticas de marketing e comercialização.

A respeito dos impactos resultantes da introdução de inovação na empresa, a Dígitro enumera como muito importantes os seguintes: a ampliação da gama de produtos ofertados, o aumento da qualidade dos produtos, a manutenção da participação nos mercados de atuação, o aumento da participação no mercado interno, a redução dos custos de trabalho e de insumos, o enquadramento em regulamentações e normas padrão relativas ao mercado interno e ainda a redução do impacto sobre o meio ambiente.

Como atividades inovativas rotineiras, a empresa realiza pesquisa e desenvolvimento (P\&D) internamente; investe na aquisição de máquinas e equipamentos para a introdução de melhorias tecnológicas de produtos e processos; investe na aquisição de outras tecnologias, tais como softwares e licenças ou acordos de transferência de tecnologias; desenvolve programa de treinamento orientado à introdução de produtos/processos tecnologicamente novos ou significativamente melhorados; realiza programas de gestão da qualidade e modernização organizacional e busca novas formas de comercialização e distribuição para o mercado de produtos novos ou significativamente melhorados.

Especificamente sobre a frequência e organização das atividades de P\&D da 
Dígitro, verifica-se que estas se apresentam de forma contínua e descentralizada, porém realizadas unicamente na matriz da empresa. A Dígitro apresentou, nos anos de 2006 a 2010, uma média de $13 \%$ do percentual de seu faturamento utilizado em atividades de P\&D que contribuíram para o desenvolvimento de novos produtos ou processos. Desta forma, enquadra-se no percentual de 24,14\% das empresas catarinenses que apresentaram investimento na faixa de $10,1 \%$ a $20 \%$ em relação ao faturamento, destacando-se em relação ao investimento nacional, que foi de 5,85\% nesta categoria, conforme já observado anteriormente.

Dentre as fontes de financiamento, a empresa capta recursos do BNDES, FINEP e Inova Brasil, contando, assim, com recursos públicos para o desenvolvimento das atividades inovativas. A Dígitro não tem por característica captar recursos de institutos privados, como bancos, por exemplo. De qualquer forma, o percentual de recursos próprios investido é sempre maior que os recursos captados, visto que estes fundos exigem uma contrapartida da empresa, que, no caso da Dígitro, é normalmente o dobro do solicitado.

As fontes de informação utilizadas para a realização de inovações na Dígitro são tanto internas como externas, com destaque para a linha de produção da própria empresa, clientes, universidades, concorrentes, atividades cooperativas ou joint ventures, feiras e exposições, publicações e relatórios técnicos e internet, de acordo com a Tabela 10. Dentre as fontes citadas, a linha de produção foi apontada como a mais importante para sugerir novos projetos e a participação dos clientes foi indicada como a mais importante para concluir projetos já existentes. Tal resultado é exatamente o inverso do observado na pesquisa em Santa Catarina, mas assume a tendência de que estas são as duas fontes mais citadas, em que cada uma delas assume a segunda posição em importância relativa no âmbito mo qual a outra é privilegiada.

\subsection{A interação universidade-Dígitro}

Com relação às principais fontes de informação com universidades para as atividades inovativas na Dígitro, foram consideradas como muito importantes: pessoal contratado com graduação ou pós-graduação, pesquisa encomendada à universidade, pesquisa realizada em conjunto com a universidade e a participação em redes que envolvam universidades, conforme Tabela 11.

Dos resultados produzidos pelas universidades ou institutos de pesquisa, o item apontado pela Dígitro como de maior importância foi o uso de laboratórios e metrologia, além de importância moderada atribuída aos protótipos e às novas técnicas e instrumentos. Os resultados de pesquisas foram considerados pouco importantes. 
As razões que levaram a Dígitro a buscar colaboração com as Universidades que foram destacadas como as mais importantes são a transferência de tecnologia da universidade, a contratação de pesquisa para as atividades inovativas da empresa e contatos com estudantes universitários para recrutamento, como se pode verificar na Tabela 12.

\subsection{Transferência de tecnologia e conhecimento, produtos e resultados}

A transferência dos conhecimentos científicos e tecnológicos é oportunizada pelo relacionamento maduro e pelo grau de conhecimento envolvido " $\mathrm{A}$ facilidade que a Dígitro tem com estas empresas parceiras, a transferência de tecnologia, nos dois sentidos Dígitro-Parceiro e Parceiro-Dígitro, é que ambos os laboratórios e empresa têm o mesmo grau de conhecimento.” O permanente contato entre a Dígitro e os grupos de pesquisa durante o processo de desenvolvimento de um produto ou tecnologia também aproxima as partes e facilita a interação "[...] durante todo o processo do desenvolvimento, é feita essa transferência de tecnologia.”

No que concerne aos instrumentos utilizados na transferência do conhecimento gerado na interação, a empresa mantém um canal de grande abertura com as universidades, a começar pela oferta de estágios e oportunidades de troca de experiência, além da publicação de pesquisas, dissertações e teses.

Sobre os conhecimentos relevantes transferidos entre as partes ao longo do processo de interação, a Dígitro divulga aqueles que já se converteram em soluções ou produtos propriamente ditos, mantendo sigilo para aqueles que ainda se encontram em processo de desenvolvimento. Dentre as aplicações de informática e automação para telemática já desenvolvidas, pode-se citar: Sistema de Conversão Texto-Fala (TTS): permite uma grande diversidade de aplicações em telecomunicações. Dentre elas, destaca-se a automação de URA's (Unidade de Resposta Audível). Para estas aplicações, a qualidade da voz sintetizada é de extrema relevância e gera um diferencial importantíssimo nos produtos que fazem uso de tal tecnologia. Com esse intuito, o sistema TTS desenvolvido vem recebendo diversos aprimoramentos ao longo do tempo, levando a um constante melhoramento na qualidade da síntese de fala produzida.

Sistema de Reconhecimento de Fala: esta solução possui também diferentes aplicações em portais de voz, call centers, bem como em diversos serviços de atendimento automáticos (URAs), atribuindo vanguarda, acessibilidade e segurança ao cliente-usuário. Para desenvolver tal tecnologia, o projeto possui, 
em sua equipe executora, especialistas das mais diversas áreas, especialmente em linguística, processamento de sinais e ciências da computação. A equipe executora detém o conhecimento fundamental para realizar ajustes fonéticos necessários para aceitar regionalismos da língua portuguesa e a heterogeneidade da planta telefônica brasileira.

Sistema de Detecção de Palavras-chave (keyword spotting - KWS): de natureza semelhante ao reconhecimento de fala, a detecção de palavras-chave possibilita a busca de palavras isoladas em streams de áudio. A referida tecnologia pode ser utilizada para procurar termos de interesse em bancos de dados de gravações ou detectar sua ocorrência em tempo real. Aplicações de destaque dessa técnica incluem auxílio à auditoria de gravações em call centers e segurança pública.

Identificação de Locutor: esta tecnologia possibilita identificar o locutor presente em uma dada gravação. Para tal, o sistema compara parâmetros extraídos da gravação com aqueles de um banco contendo modelos das vozes de locutores conhecidos; caso a voz da gravação não "case” com a de qualquer um dos locutores do banco, o sistema a classifica como desconhecida. Algumas de suas possíveis aplicações são: autenticação de usuários por voz, indexação de bancos de gravações e aplicações em segurança pública.

Os resultados gerados a partir do processo de interação têm permitido não só a empresa produzir inovações em seus produtos, como também destacar-se em segmentos em que atua. "A Dígitro, pelas tecnologias desenvolvidas, ela é pioneira em produtos para a área de segurança pública, e esse resultado [...] é oriundo desta parceria feita exatamente com o LINSE. Então todos esses produtos que a gente citou aqui, Sistema de Conversão Texto-Fala, Sistema de Reconhecimento de Fala, foram agregados aos nossos produtos, e são pioneiros, são produtos que estão alavancando a empresa." A empresa passou a contar com um conhecimento específico sobre estas tecnologias que só foi possível graças à interação.

\subsection{Dinâmica da interação}

Com relação à escolha dos parceiros, foi colocado que "existem muitas empresas querendo fechar parcerias com a Dígitro”. Neste caso, são levado em conta a qualidade do trabalho desenvolvido, a capacidade do pessoal envolvido e o know how acumulado ao longo do tempo, motivos pelos quais a empresa prefere manter sempre a parceria com os mesmos grupos de pesquisa. A Dígitro valoriza a trajetória de interação construída e o histórico de relacionamento com os parceiros. Sobre a escolha de instituições distantes geograficamente 
(Pernambuco e Ceará), a empresa busca cumprir a exigência da lei da informática que estabelece investimentos nas regiões Norte e Nordeste do país.

A Dígitro não enfrenta dificuldades para firmar parcerias, pois possui grande abertura com universidades e é constantemente procurada por instituições para desenvolver projetos conjuntos. O maior desafio enfrentado é justamente criar novas ideias. "[...] nós temos [...] grandes parceiros, o que nos faltam são ideias, pra poder gerar novos produtos [...] temos grandes parceiros, e o que faltam são projetos.”

No estabelecimento da relação com a universidade, a área da empresa que mais interage com os grupos de pesquisa é o setor de desenvolvimento, embora a área financeira atue como suporte, no acompanhamento dos contratos e pagamentos. "A área de desenvolvimento nos encaminha relatórios de como estão estes projetos, de que forma o dinheiro está sendo aplicado, aí, estes relatórios serão enviados para fazer a prestação do dinheiro recebido (pela lei da informática).”

O relacionamento entre as equipes envolvidas na interação, tanto da Dígitro como das universidades, é contínuo e bastante facilitado pelo uso das tecnologias de comunicação, como o sistema de comunicação visual online que permite reuniões sem que as pessoas estejam presentes na empresa. De qualquer forma, há facilidade em realizar reuniões presenciais, em função da proximidade com a UFSC, o que é comum acontecer tanto na empresa como na Universidade. "Nós temos reuniões semanais, todas as terças-feiras, então esta equipe da Federal se desloca aqui, fazem as reuniões, ou nós vamos lá fazer estas reuniões". A comunicação também é facilitada pelo tempo em que as parcerias estão consolidadas e pelo conhecimento de ambas as partes.

Já na interação com o Instituto Atlântico (PE) e com a Universidade Federal do Ceará (UFC), a distância atrapalha um pouco, embora os professores responsáveis por estas instituições façam visitas à empresa. Neste caso, são feitas vídeo-conferências semanais, com base em um cronograma detalhado que especifica tudo o que será trabalhado naquela semana. "Nós Dígitro temos um acompanhamento quase que presencial com nossos parceiros, através dos cronogramas de execução.”

Graças ao bom relacionamento firmado com os parceiros, praticamente não existem conflitos na interação. Não há registro de quebra de contrato, apenas atraso na entrega dos resultados pactuados. "Esses atrasos são programados e foram previstos, durante a execução. Nada tão crítico assim, que levaria a uma quebra (de contrato) [...]”. Muitas vezes, inclusive, estes atrasos são decorrentes de questões operacionais, como por exemplo, a demora na importação de algum equipamento. 


\subsection{Aspectos institucionais}

No que tange às questões institucionais do processo de interação, são firmados contratos com os grupos de pesquisa da universidade, cujas renovações são feitas anualmente. Existe um contrato padrão "nós definimos ali os valores, as tecnologias que vão ser desenvolvidas, os prazos de execução, a questão da confidencialidade das tecnologias desenvolvidas, e eles acabam seguindo sempre um modelo padrão.” Há também a possibilidade de se estabelecerem aditivos contratuais para incluir outras questões que possam surgir durante o desenvolvimento do projeto. Os contratos dão origem ao plano de trabalho, no qual há um maior detalhamento das tarefas e responsabilidades.

No que se refere a propriedade intelectual do conhecimento desenvolvido na interação, há contratualmente definida uma cláusula que assegura o sigilo do projeto, durante o seu desenvolvimento, após este período, a empresa permite a divulgação dos resultados. "[...] a Dígitro dá abertura para os laboratórios executarem estes materiais em trabalhos acadêmicos. Então, muitos destes projetos acabam virando dissertações de mestrado, viram materiais de teses de doutorado." Além dos trabalhos acadêmicos, projetos oriundos das parcerias também são apresentados em feiras internacionais de tecnologia. Todos os projetos são desenvolvidos na modalidade de patentes abertas, que são patentes de acesso liberado ao público, a empresa não trabalha com outro tipo de patente para assegurar a propriedade industrial.

A respeito das pessoas envolvidas na interação e suas responsabilidades, da parte da Dígitro, a aprovação dos contratos é realizada pelo vice-presidente de tecnologia, em conjunto com os gerentes funcionais. O gerenciamento dos projetos é de responsabilidade do gerente de desenvolvimento (soluções em tecnologia e embarcados) e o acompanhamento do desenvolvimento dos produtos e processos cabe ao analista de soluções em tecnologia e embarcados. Na questão financeira, o gerente financeiro e o assistente técnico de suporte a projetos especiais são responsáveis pelos investimentos, prestações de conta e acompanhamento dos resultados. "O acompanhamento de resultado é feito por todas as pessoas da equipe. Nós (financeiro) porque precisamos comprovar e eles (desenvolvimento) porque precisam desta tecnologia." Da parte da universidade, os responsáveis são os professores dos laboratórios com os quais são firmados os contratos.

Sobre os investimentos realizados, conforme já mencionado, a empresa utiliza os recursos da Lei de Informática, aplicando, inclusive, uma proporção maior de recursos próprios do que aqueles exigidos legalmente. "Nós não temos uma limitação financeira. Sobram parceiros querendo receber capitais, os nossos recursos. Mas como a empresa já tem parceiros pré-definidos, a empresa acaba aplicando esse recurso só neles.” 


\section{Considerações finais}

O estudo sobre a interação universidade e empresa demonstra que em SC, a exemplo do que ocorre no Brasil, empresas realizam esforços em processos inovativos relacionados ao aperfeiçoamento de produtos e processos existentes, em primeira instância, e em desenvolvimento de novos produtos ou processos para a empresa e para o país, em segundo plano. Nestes termos, as empresas procuram procedimentos incrementais voltados a modificar $o$ padrão produtivo existente a lançar produto e processo novo, em forma original, no mercado. Da mesma forma, tanto em nível estadual como nacional, a principal fonte de informação para sugerir novos projetos são os clientes. Preferem recorrer à opinião de quem utiliza, bem como sinaliza tendência dos produtos no mercado. Tal qual recebe relevância, em ambas as esferas, a linha de produção da empresa para concluir projetos, revelando, assim, a importância das rotinas do cotidiano para definir mudanças na trajetória tecnológica.

As universidades e os institutos de pesquisa também recebem tratamento especial, seja no Estado, seja no país, pois figuram entre as principais fontes de informação citadas pelas empresas. Dentro deste quadro, dão mais importância para a função de sugerir projetos do que de concluir projetos. A principal razão para a colaboração com a universidade citada pelas empresas catarinenses foi a transferência de tecnologia expressa pela compra de pacote tecnológico desenvolvido na universidade e adequado pela empresa. Para as empresas brasileiras, foi a utilização da infraestrutura para pesquisa e testes para produtos e processos, o que demonstra o envolvimento com a universidade para fazer uso de sua pesquisa e dos serviços tecnológicos disponíveis.

Considerando a interação das empresas com universidade em SC, sob a perspectiva do setor por intensidade tecnológica, registram-se informações relevantes para as empresas situadas em indústrias de alta e média-alta tecnologia, em relação às demais faixas. São estas empresas que mais realizam inovações de produto e processo, tanto na forma de aperfeiçoamento como novo para o mercado. Tal resultado está em consonância com a dedicação maior de recursos para $\mathrm{P} \& \mathrm{D}$ em relação às empresas situadas no bloco das com menor conteúdo tecnológico. São tais empresas que representam a Universidade entre as principais fontes, para sugestão e conclusão de projetos voltados ao desenvolvimento inovativo. Nesta perspectiva, apontam esta fonte de informação importante para realizar pesquisa encomendada e para concluir pesquisa em conjunto, tendo em grande monta como área de conhecimento de engenharia elétrica, engenharia mecânica e ciência de computação.

O estudo de caso da Dígitro Tecnologia Ltda. ilustra uma relação sólida com a universidade, num processo de cooperação que tem produzido resultados 
positivos do ponto de vista de desenvolvimento tecnológico. A interação com a UFSC, em grande monta, e com a UFCE e o Instituto Atlântico, em menor escala, contribui tanto para a introdução de novos produtos quanto de novos processos, seja no desenvolvimento ou aperfeiçoamento dos já existentes, seja na colocação de novos para o mercado. Em particular, a relação com a UFSC ultrapassa uma década e meia, garantida por vários fatores, dentre os quais: desenvolvimento contínuo da atividade inovativa, elevado gasto anual em P\&D, significativo número de trabalhadores com nível educacional superior, relacionamento maduro e estável entre as partes, cumprimento dos contratos estabelecidos e presença constante de pesquisadores em etapas de sugestão e de conclusão de já existentes. Para a Dígitro, as principais razões para a colaboração com as universidades são a transferência de tecnologia, a possibilidade de contratar pesquisas complementares e ainda fazer contatos com estudantes universitários para futura contratação. Assim como a Dígitro, outras empresas poderiam também se beneficiar de um relacionamento com as universidades, marcado por uma trajetória de troca de conhecimento construída ao longo do tempo.

\section{Referências}

BONACCORSI, A. \& PICCALUGA, A. A. (1994). “Theoretical framework for the evaluation of-university-industry relationships." $R \& D$ Management 24(3).

BERNARDES, A. \& ALBUQUERQUE E. M. (2003). "Cross-over, thresholds and the interactions between science and technology: lessons for lessdeveloped countries." Research Policy 2(5): 867-887.

BRISOLLA, S. N. (1998). Interação universidade-empresa: como seria se fosse.” In: INSTITUTO BRASILEIRO INFORMAÇÃO EM C\&T. (Org.). Interação Universidade-Empresa. Brasília: IBICT, pp. 76-98.

DUTRÉNIT, G. \& ARZA, V. (2010). "Channels and benefits of interactions between public research organisations and industry: comparing four Latin American countries." Science and Public Policy 37(7): 541-553.

ETZKOWITZ, H. \& LEYDESDORFF, L. (2000). "The dynamics of innovation: from national systems and "mode 2 " to a triple helix of university-industrygovernment relations.” Research Policy 29(2): 109-123.

FERNANDES, A. C. \& CAMPELO DE SOUZA, B. \& STANFORD SILVA, A. 
\& SUZIGAN, W. \& CHAVES, C. V. \& ALBUQUERQUE, E, M. (2010). "Academy-industry links in Brazil: evidence about channels and benefits for firms and researchers.” Science and Public Policy 37(7): 485-498.

FREEMAN, C. (1995). "The national system of innovation in historical perspective." Cambridge Journal of Economics 19: 5-24.

LEYDERSDORFF, L. \& ETZKOWITZ, H. (1998). "The triple helix as a model for innovation studies." Science \& Public Policy 25(3): 195-203.

LASTRES, H. M. M \& FERRAZ, J. C. (1999). "Economia da Informação, do conhecimento e do aprendizado.” In: LASTRES, M. H. \& ALBAGLI, S. (org). Informação e globalização na era do conhecimento. Rio de Janeiro: Campus, pp. 27-57.

LUNDVALL, B. (1992). National systems of innovation: towards a theory of innovation and interactive learning. London: Pinter Publishers.

MACULAN, A. M. (2005). "Capacitação tecnológica e inovação nas empresas brasileiras: balanço e perspectivas.” Cadernos Ebape Br - Edição Especial - Gestão Tecnológica e Inovação: Experiências no Brasil e na América Latina. Rio de Janeiro: EBAPE/FGV, pp. 1-18.

NELSON, R. (1993). National Innovation Systems: a comparative analysis. New York: Oxford University, 1993.

PINHO, M. (2011). A Interação Universidade-Empresa Segundo as Categorias de Intensidade Tecnológica: Uma primeira Leitura dos dados do Survey de Empresas. São Paulo, UNICAMP.

RAPINI, M. S. \& CHAVES, C. V. \& ALBUQUERQUE, E. M. \& SILVA, L. \& SOUZA, S. G. A. \& RIGHI, H. M. \& CRUZ, W. M. S. (2009). "University industry interactions in an immature system of innovation: evidence from Minas Gerais, Brazil.” Science and Public Policy 36(5): 373-386.

RIGHI, H, M. (2009). O Panorama da Interação entre Universidades e a Indústria no Brasil. Campinas: Dissertação de Mestrado. Universidade Estadual de Campinas, Instituto de Geociências.

SAAD, M. \& ZAWDIE, G. (2011). "Introduction to special issue: The emerging role of universities in socio-economic development through knowledge networking." Science and Public Policy 38(1): 3-6.

SÁBATO, J. \& BONATA, N. (1968). "La ciencia e la tecnología en el desarrollo futuro de América Latina.” Revista Integración latino-americana 1(3): 15-36. 
CARIO, S. A. F. \& LEMOS, D. C. \& SIMONINI, A. Avaliação da interação universidade-empresa...

SCHUMPETER, J. A. (1982). Teoria do desenvolvimento econômico: uma investigação sobre lucros, capital, crédito, juro e ciclo econômico. São Paulo: Abril Cultural.

SEGATTO-MENDES, A. P. \& SBRAGIA, R. (2002). "O Processo de cooperação universidade-empresa em universidades brasileiras." Revista de Administração da USP (RAUSP) 37(4): 58-71.

STUZ, J. (2000). “The university-industry-government relations in Latin America." Research Policy 29: 279-290. 
TABELA 1. CARACTERIZAÇÃO DAS EMPRESAS POR INTENSIDADE TECNOLÓGICA, BRASIL E SC - 2009

\begin{tabular}{|c|c|c|c|c|c|c|c|c|c|c|c|}
\hline \multirow{2}{*}{\multicolumn{2}{|c|}{$\begin{array}{l}\text { Intensidade } \\
\text { Tecnológica }\end{array}$}} & \multicolumn{2}{|c|}{ Micro } & \multicolumn{2}{|c|}{ Pequena } & \multicolumn{2}{|c|}{ Média } & \multicolumn{2}{|c|}{ Grande } & \multicolumn{2}{|c|}{ Total } \\
\hline & & $\mathrm{SC}$ & BRA & $\mathrm{SC}$ & BRA & SC & BRA & $\mathrm{SC}$ & BRA & $\mathrm{SC}$ & BRA \\
\hline \multirow{5}{*}{ 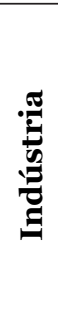 } & $\begin{array}{l}\text { Indústrias de } \\
\text { Alta Tecnologia }\end{array}$ & - & 7 & - & 12 & - & 20 & 2 & 9 & 2 & 48 \\
\hline & $\begin{array}{l}\text { Indústrias de } \\
\text { Média-Alta Tecnologia }\end{array}$ & 1 & 5 & 1 & 8 & 1 & 21 & 3 & 20 & 6 & 54 \\
\hline & $\begin{array}{l}\text { Indústrias de } \\
\text { Média-Baixa Tecnologia }\end{array}$ & - & 2 & 1 & 11 & 1 & 14 & 2 & 24 & 4 & 51 \\
\hline & $\begin{array}{l}\text { Indústrias de } \\
\text { Baixa Tecnologia }\end{array}$ & - & 6 & - & 13 & - & 17 & 2 & 15 & 2 & 51 \\
\hline & Indústria Extrativa & - & - & - & 2 & - & 4 & - & 5 & - & 11 \\
\hline \multicolumn{2}{|c|}{ Subtotal: Indústria } & $\mathbf{1}$ & 20 & 2 & 46 & 2 & 76 & 9 & 73 & 14 & 215 \\
\hline \multirow{5}{*}{ • } & Engenharia e P\&D & - & 4 & 2 & 9 & - & 2 & 1 & 7 & 3 & 22 \\
\hline & $\begin{array}{l}\text { Informação } \\
\text { e Comunicação }\end{array}$ & - & 4 & 1 & 10 & - & 1 & 1 & 6 & 2 & 21 \\
\hline & $\begin{array}{l}\text { Serviços de } \\
\text { Utilidade Pública }\end{array}$ & - & 1 & - & 2 & 1 & 2 & 3 & 23 & 4 & 28 \\
\hline & Outros Serviços & 1 & 1 & - & 5 & 1 & 1 & 4 & 14 & 6 & 21 \\
\hline & $\begin{array}{l}\text { Agropecuária } \\
\text { e Silvicultura }\end{array}$ & - & 3 & - & 3 & - & - & - & 12 & - & 18 \\
\hline \multicolumn{2}{|c|}{ Subtotal: Serviço } & 1 & 13 & 3 & 29 & 2 & 6 & 9 & 62 & 15 & 110 \\
\hline \multicolumn{2}{|c|}{ TOTAL } & 2 & 33 & 5 & 75 & 4 & 82 & 18 & 135 & 29 & 325 \\
\hline
\end{tabular}

NOTA: Tamanho: Classificação SEBRAE (Indústria: Micro: até 19 empregados; Pequena: de 20 a 99 empregados; Média: de 100 a 499 empregados; Grande: 500 e mais empregados - Serviços: Micro: até 9 empregados; Pequena: de 10 a 49 empregados; Média: de 50 a 99 empregados; Grande 100 empregados).

FONTE: Pesquisa de Campo, 2009. 
CARIO, S. A. F. \& LEMOS, D. C. \& SIMONINI, A. Avaliação da interação universidade-empresa...

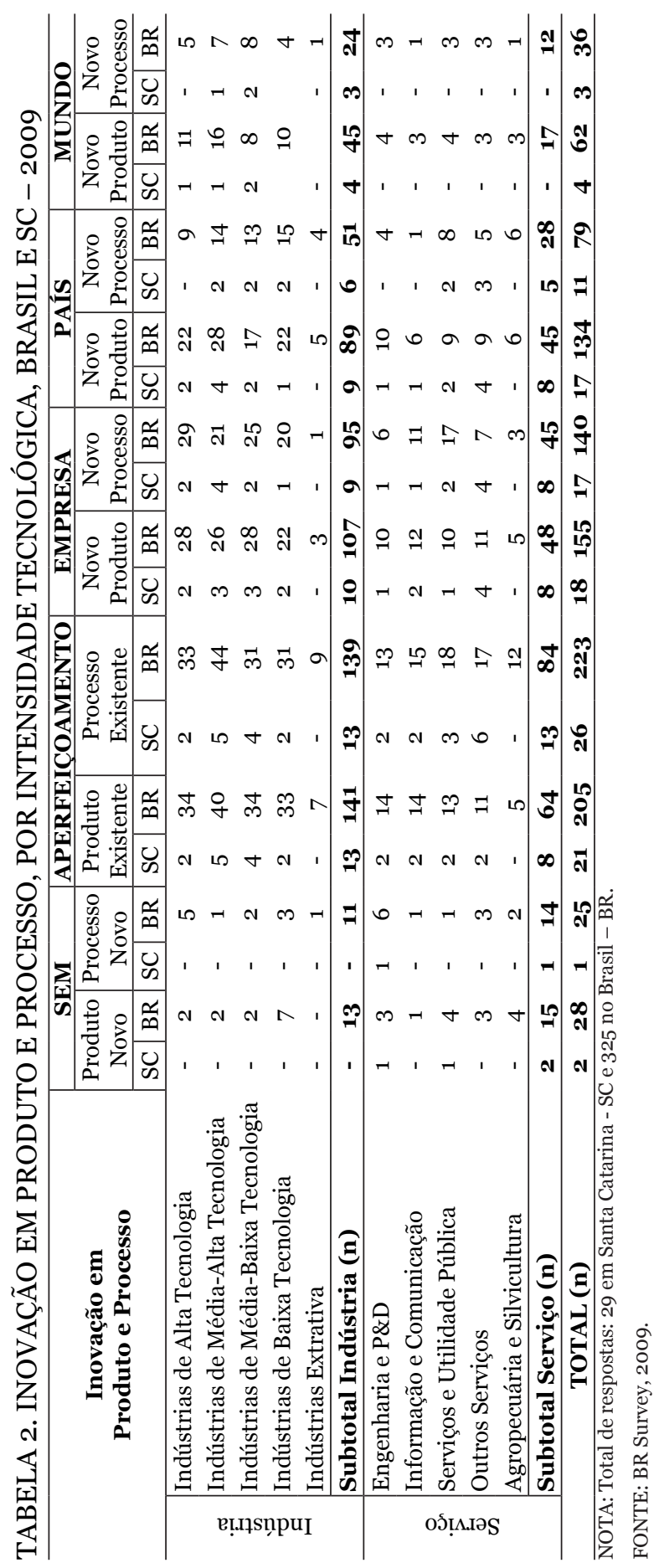


CARIO, S. A. F. \& LEMOS, D. C. \& SIMONINI, A. Avaliação da interação universidade-empresa...

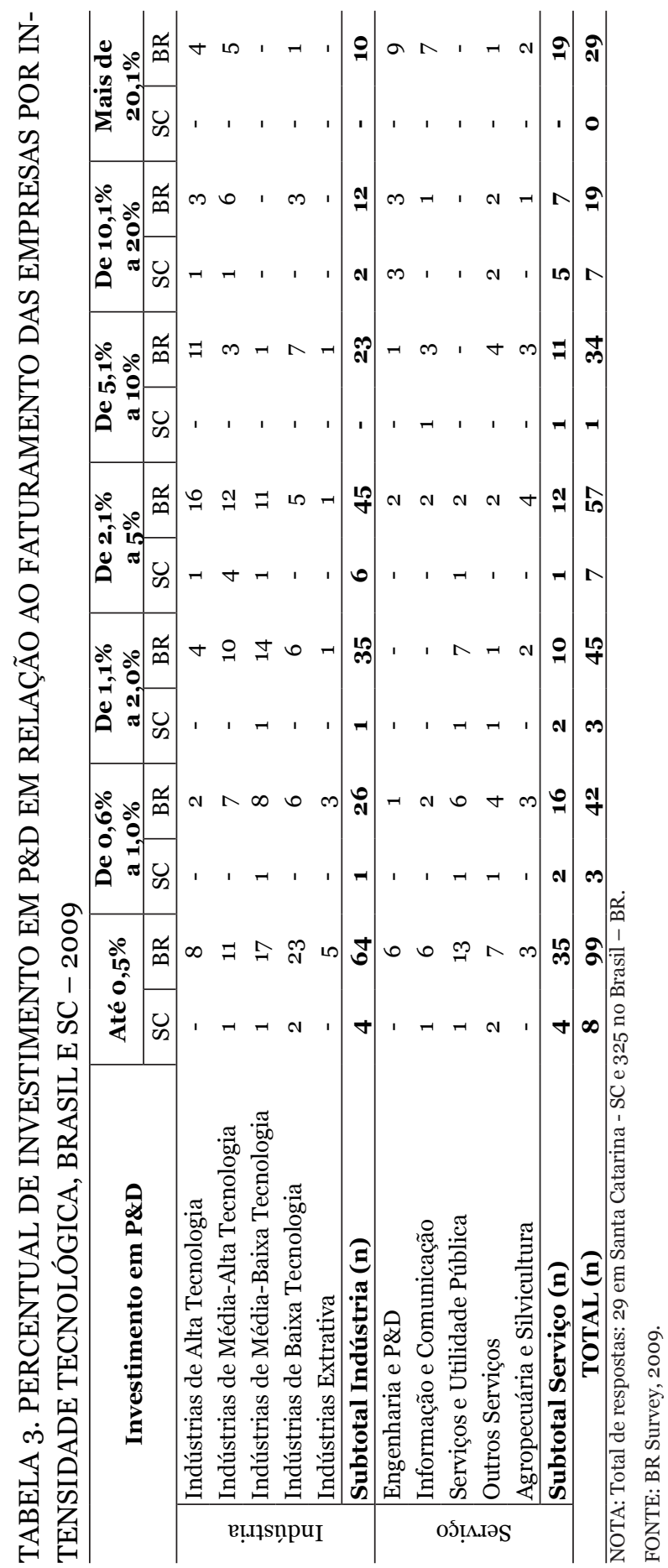


CARIO, S. A. F. \& LEMOS, D. C. \& SIMONINI, A. Avaliação da interação universidade-empresa...

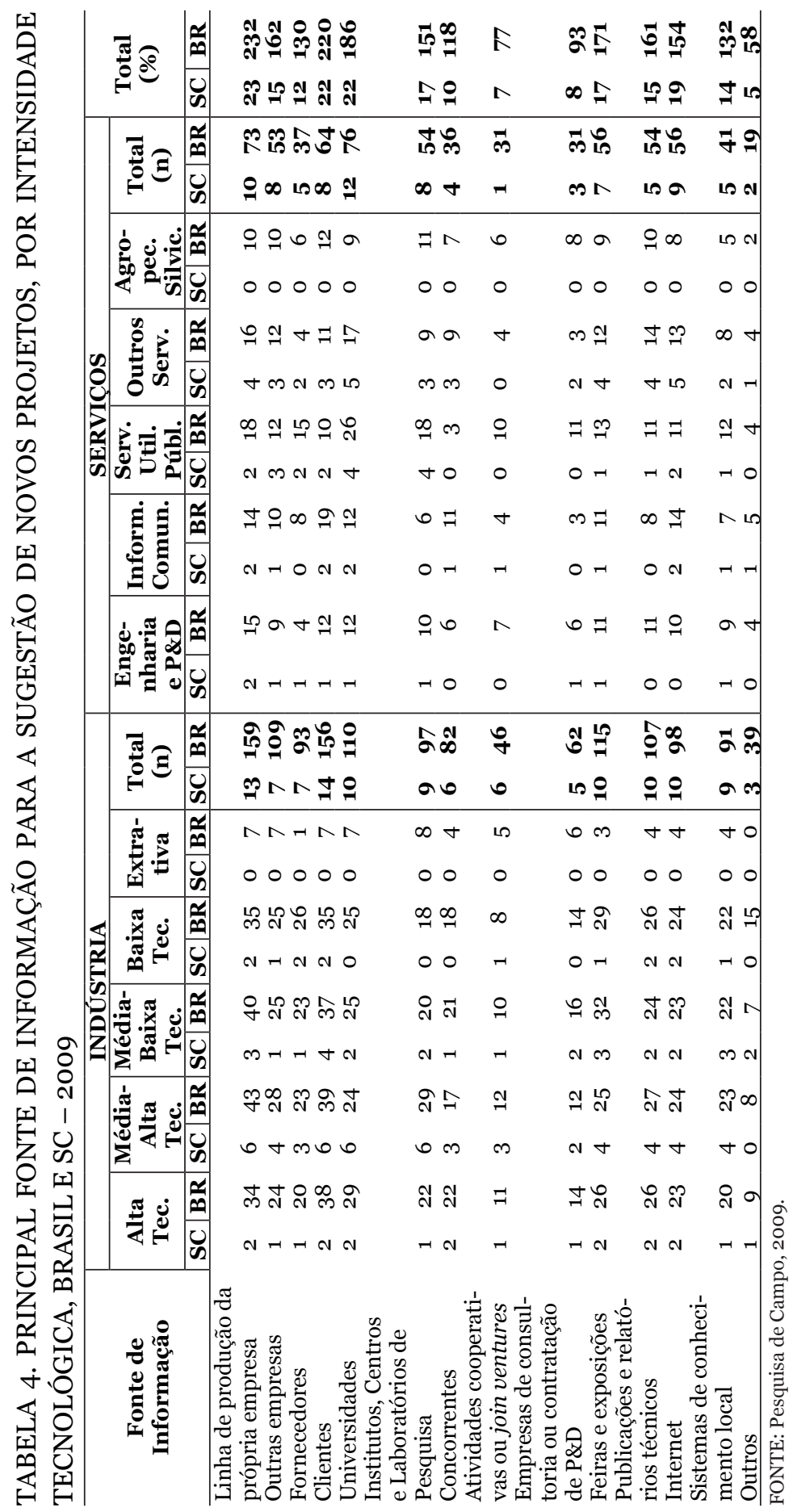




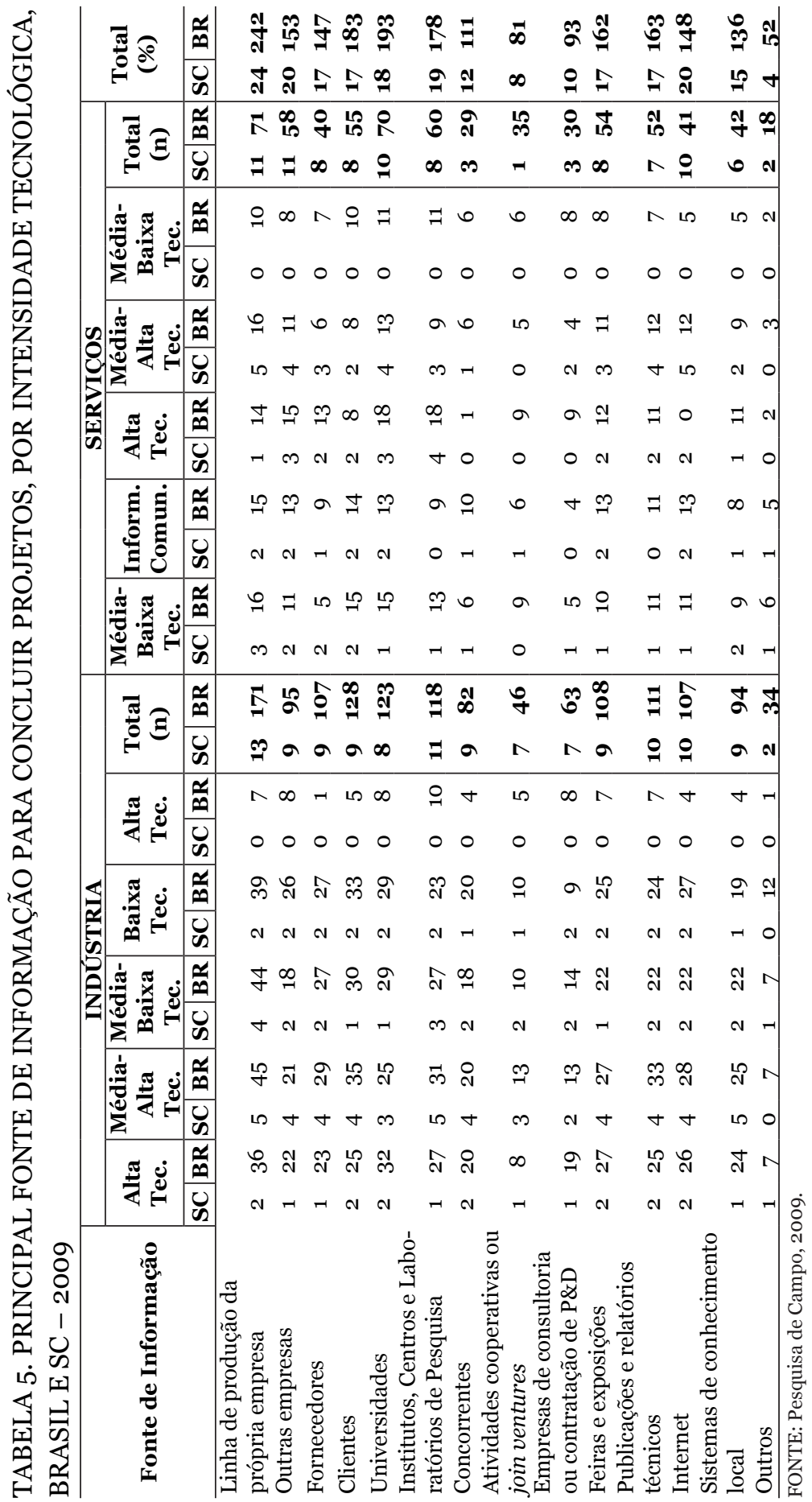


CARIO, S. A. F. \& LEMOS, D. C. \& SIMONINI, A. Avaliação da interação universidade-empresa...

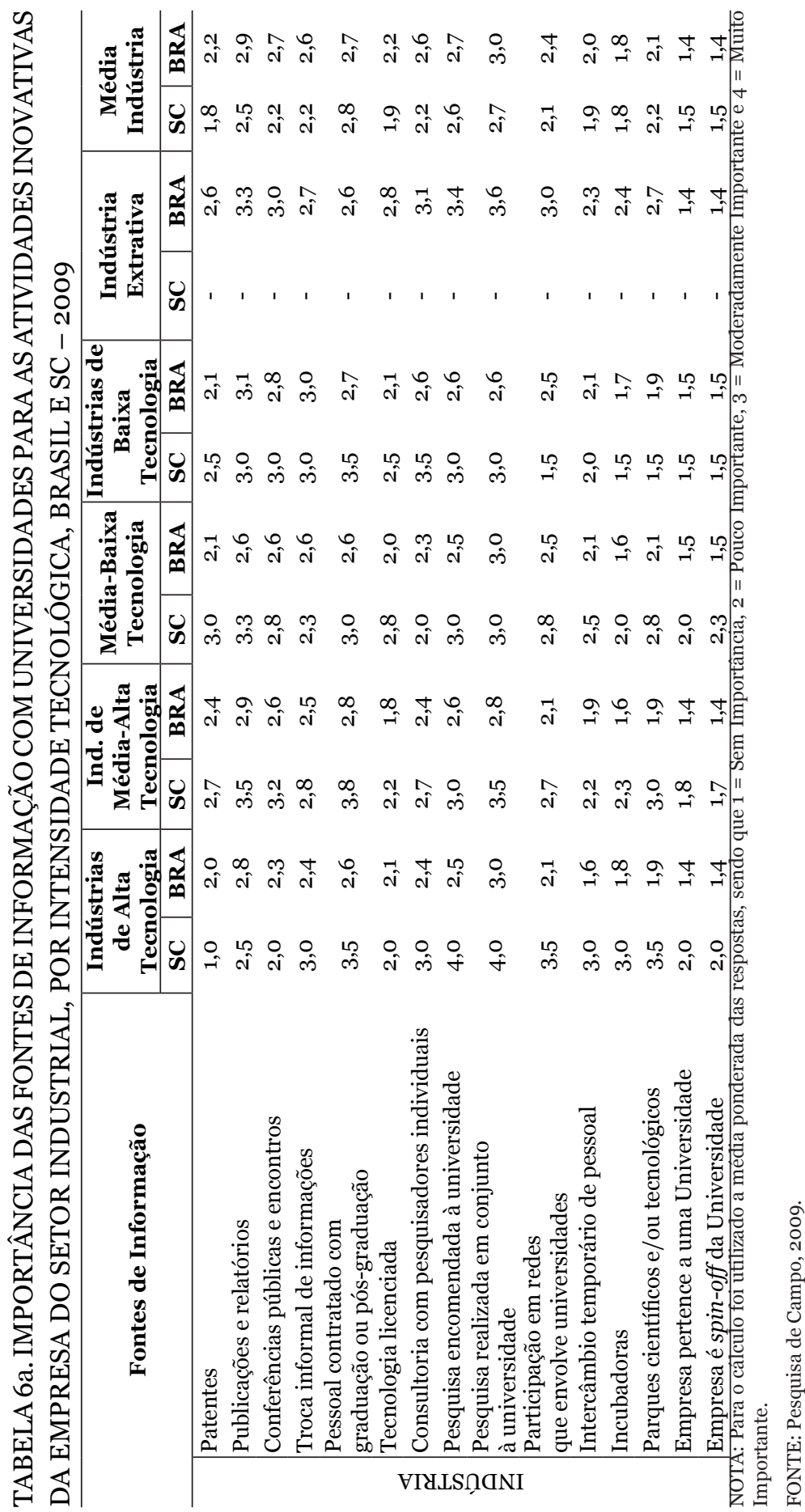


CARIO, S. A. F. \& LEMOS, D. C. \& SIMONINI, A. Avaliação da interação universidade-empresa...

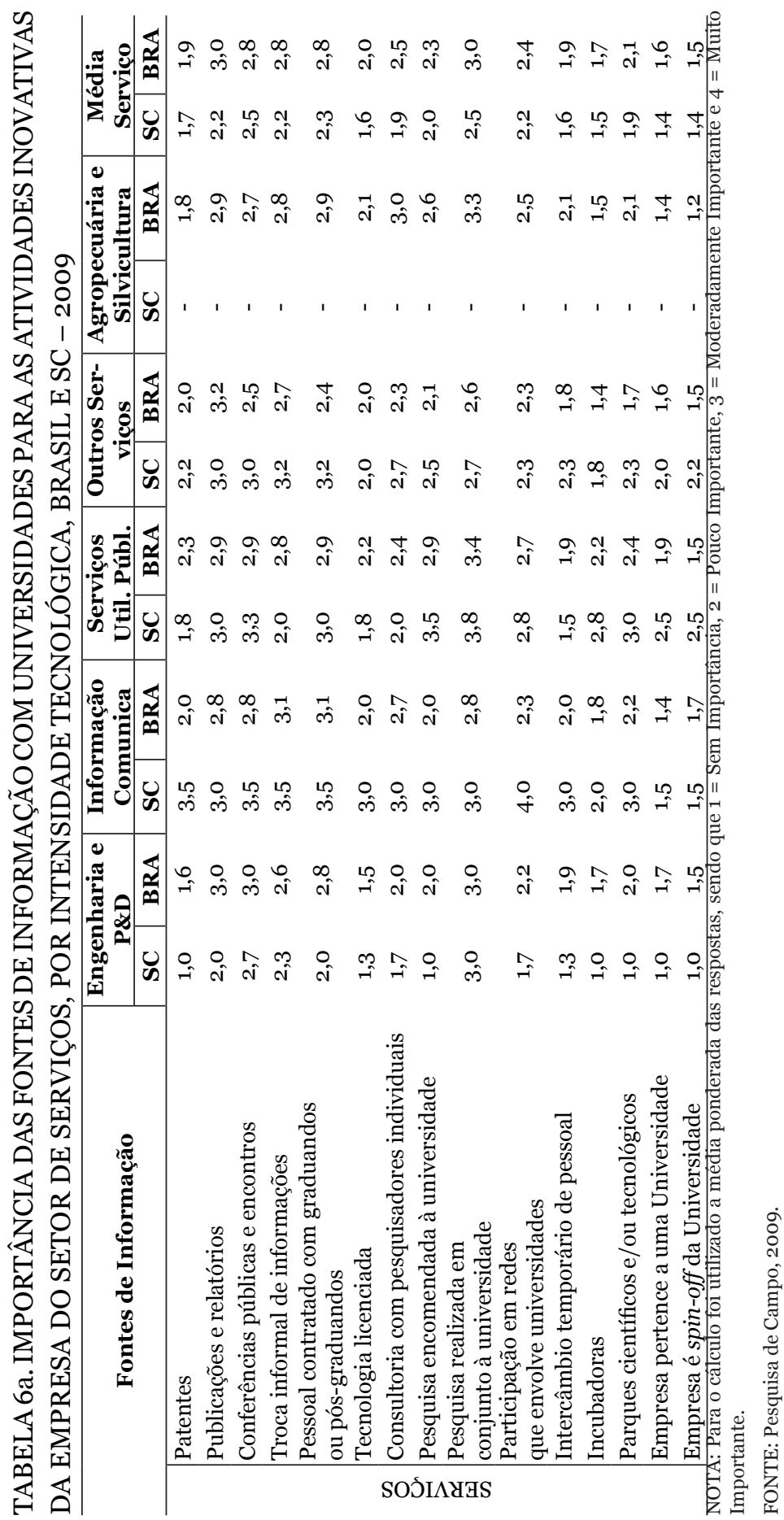


CARIO, S. A. F. \& LEMOS, D. C. \& SIMONINI, A. Avaliação da interação universidade-empresa...

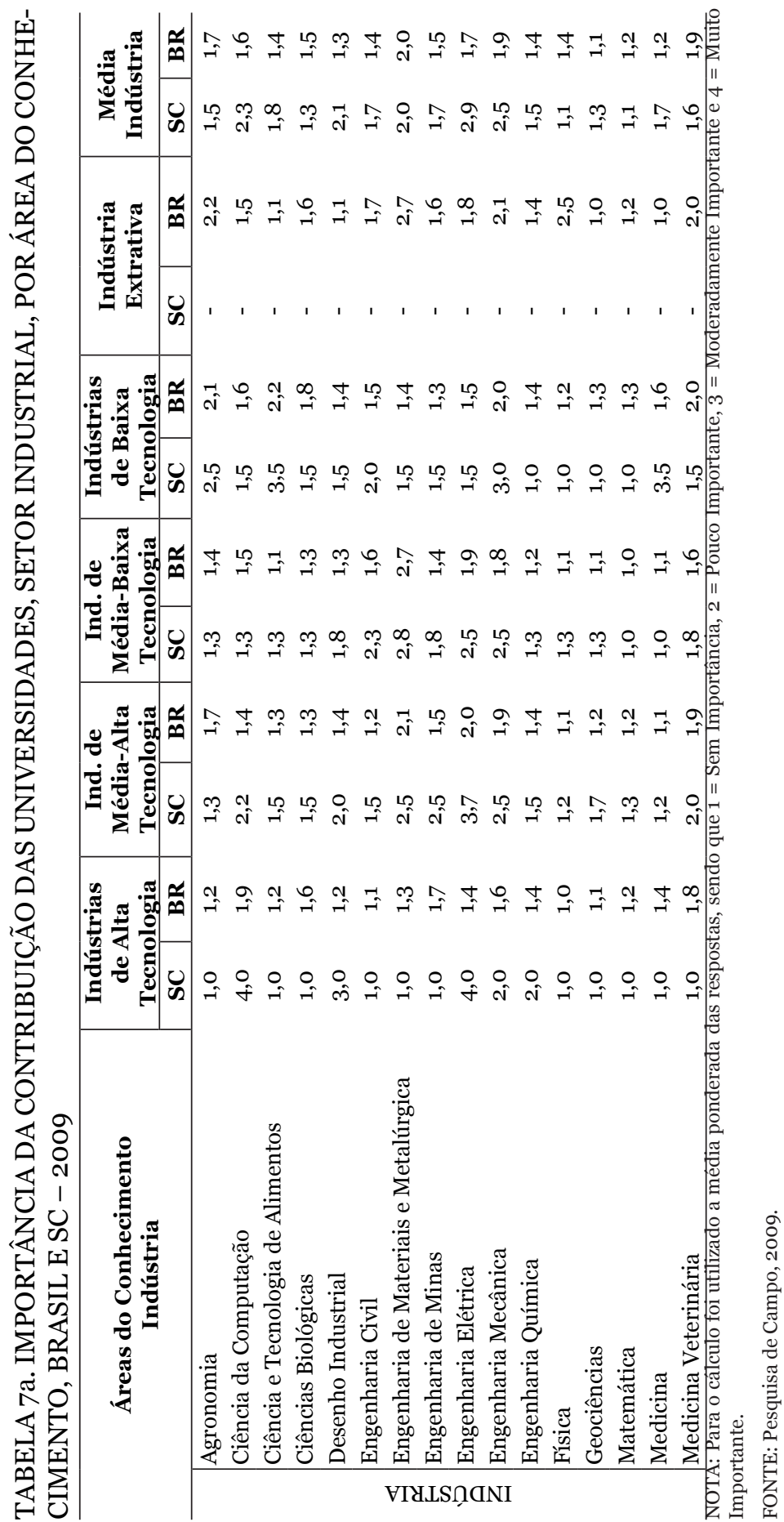


CARIO, S. A. F. \& LEMOS, D. C. \& SIMONINI, A. Avaliação da interação universidade-empresa...

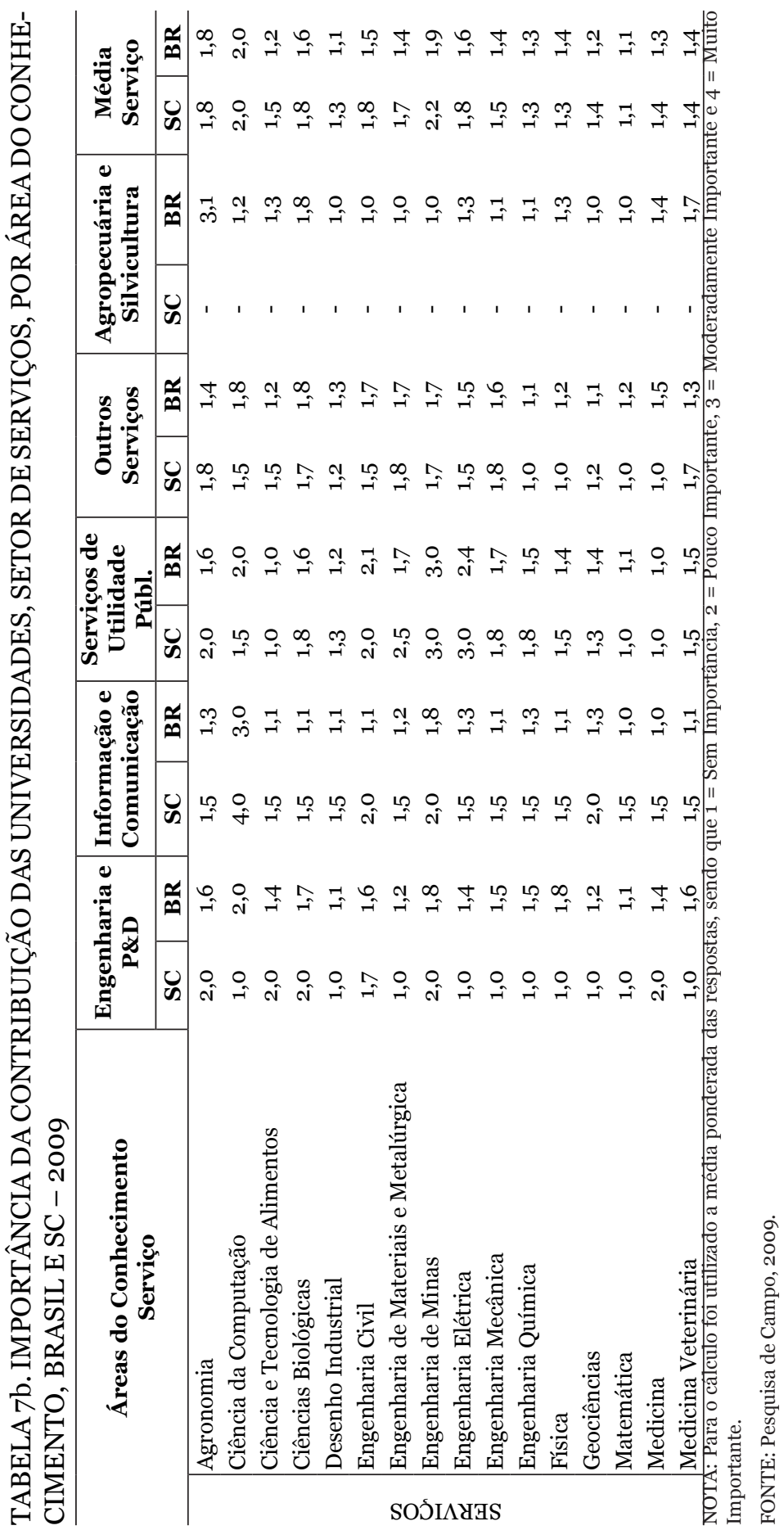


CARIO, S. A. F. \& LEMOS, D. C. \& SIMONINI, A. Avaliação da interação universidade-empresa...

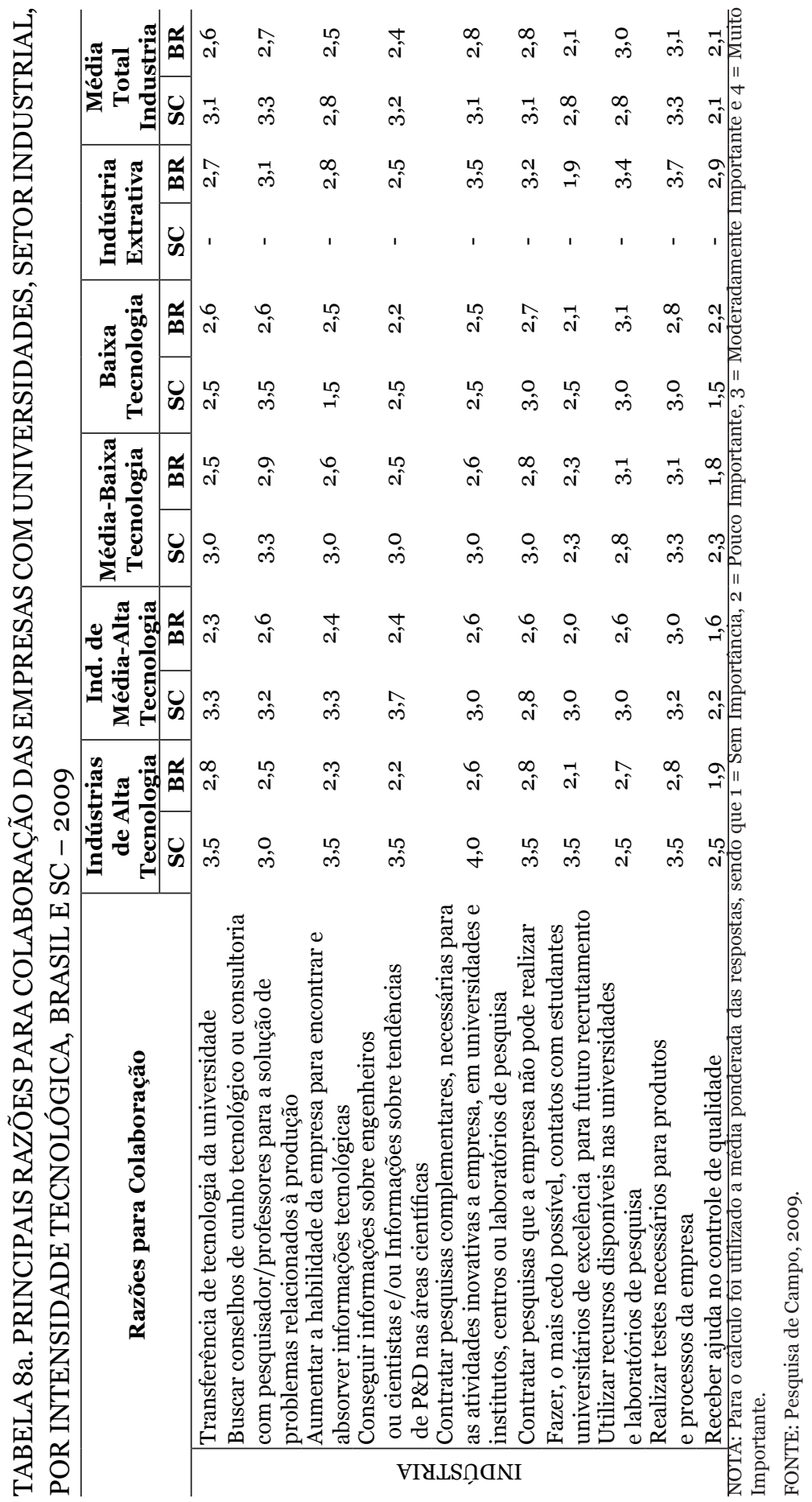


CARIO, S. A. F. \& LEMOS, D. C. \& SIMONINI, A. Avaliação da interação universidade-empresa...

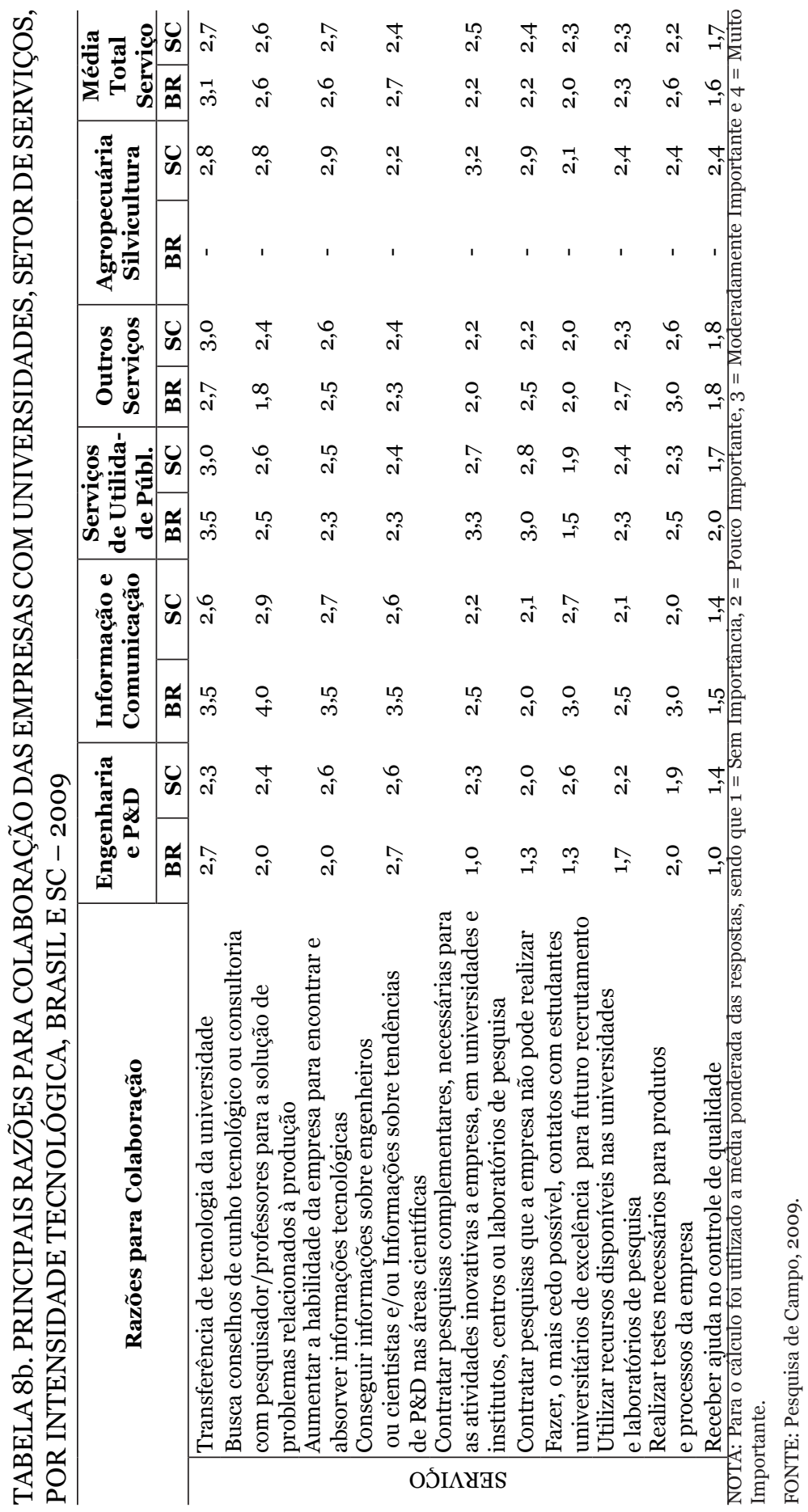




\begin{tabular}{|c|c|c|}
\hline $\begin{array}{c}\text { Produtos e } \\
\text { Servicos }\end{array}$ & Tipos & Descrição \\
\hline Soluções & $\begin{array}{l}\text { PABX } \\
\text { Call Center } \\
\text { Redes } \\
\text { Convergentes } \\
\end{array}$ & $\begin{array}{l}\text { Central telefônica privada } \\
\text { Central de atendimento que faz a interface entre o cliente } \\
\text { e a empresa } \\
\text { Agrupar o uso de tecnologias para unificar redes de voz e } \\
\text { dados }\end{array}$ \\
\hline $\begin{array}{l}\text { Tecnologias } \\
\text { Dígitro }\end{array}$ & $\begin{array}{l}\text { Plataformas } \\
\text { CT }^{1} \text { Dígitro } \\
\text { VoIP e VoFR } \\
\text { Reconhecimento } \\
\text { de fala } \\
\text { Síntese de fala }\end{array}$ & $\begin{array}{l}\text { Centrais telefônicas privadas e de alto desempenho } \\
\text { Reúne todas as funções em um equipamento } \\
\text { Conexões que permitem que uma empresa esteja inter- } \\
\text { ligada integrando voz e dados em um mesmo meio de } \\
\text { transmissão. } \\
\text { Total interação do usuário com o sistema através do co- } \\
\text { mando de voz } \\
\text { Permitem veiculação de informação por meio da fala sin- } \\
\text { tetizada }\end{array}$ \\
\hline $\begin{array}{l}\text { Dígitro } \\
\text { Service }\end{array}$ & $\begin{array}{l}\text { Supervisão } \\
\text { Performance } \\
\text { Tarifação } \\
\text { Gestão Telecom }\end{array}$ & $\begin{array}{l}\text { Serviço de monitoração de equipamentos } \\
\text { Processo de gerencia de desempenho e de dimensionamento } \\
\text { dos equipamentos da rede } \\
\text { Indicam o perfil de consumo dos clientes visando reduzir } \\
\text { os custos } \\
\text { Gestão de contratos de telecomunicação visando reduzir } \\
\text { os custos }\end{array}$ \\
\hline
\end{tabular}

FONTE: Pesquisa de Campo, 2009.

\section{TABELA 10. FONTES DE INFORMAÇÃO PARA SUGESTÃO DE NOVOS PROJETOS OU PARA CONCLUIR PROJETOS EXISTENTES}

\begin{tabular}{l|c|c|c|c}
\hline \multirow{2}{*}{ Fontes de Informação } & \multicolumn{2}{c}{$\begin{array}{c}\text { Sugerir novos } \\
\text { projetos }\end{array}$} & $\begin{array}{c}\text { Concluir proje- } \\
\text { tos existentes }\end{array}$ \\
\cline { 2 - 5 } & Sim & Não & Sim & Não \\
\hline Linha de produção da própria empresa & $\mathrm{X}$ & & $\mathrm{X}$ & \\
Outras Empresas & & $\mathrm{X}$ & & $\mathrm{X}$ \\
$\begin{array}{l}\text { Fornecedores } \\
\text { Clientes }\end{array}$ & $\mathrm{X}$ & $\mathrm{X}$ & $\mathrm{X}$ & $\mathrm{X}$ \\
Universidades & $\mathrm{X}$ & & $\mathrm{X}$ & \\
Institutos Centros e Laboratórios de Pesquisa & & $\mathrm{X}$ & & $\mathrm{X}$ \\
Concorrentes & $\mathrm{X}$ & & $\mathrm{X}$ & \\
Atividades cooperativas ou join ventures & $\mathrm{X}$ & & $\mathrm{X}$ & \\
Empresas de consultoria ou contratação de P\&D & & $\mathrm{X}$ & & $\mathrm{X}$ \\
Feiras e exposições & $\mathrm{X}$ & & $\mathrm{X}$ & \\
Publicações e relatórios técnicos & $\mathrm{X}$ & & $\mathrm{X}$ & \\
Internet & $\mathrm{X}$ & & $\mathrm{X}$ & \\
Sistemas de conhecimento local & & $\mathrm{X}$ & & $\mathrm{X}$ \\
Outros & & $\mathrm{X}$ & & $\mathrm{X}$ \\
\hline
\end{tabular}

FONTE: pesquisa de campo, 2009. 
TABELA 11.IMPORTÂNCIA DAS FONTES DE INFORMAÇÃO COM UNIVERSIDADES PARA AS ATIVIDADES INOVATIVAS

\begin{tabular}{|c|c|c|c|c|}
\hline Itens & $\mathbf{1}$ & 2 & 3 & 4 \\
\hline Patentes & $\mathrm{X}$ & & & \\
\hline Publicações e Relatórios & & $\mathrm{X}$ & & \\
\hline Conferências públicas e encontros & & $\mathrm{X}$ & & \\
\hline Troca informal de informações & & & $\mathrm{X}$ & \\
\hline Pessoal contratado com graduação ou pós-graduação & & & & $\mathrm{X}$ \\
\hline Tecnologia licenciada & & $\mathrm{X}$ & & \\
\hline Consultoria com pesquisadores individuais & & & $\mathrm{X}$ & \\
\hline Pesquisa encomendada à universidade & & & & $\mathrm{X}$ \\
\hline Pesquisa realizada em conjunto à universidade & & & & $\mathrm{X}$ \\
\hline Participação em redes que envolvam Universidades & & & & $\mathrm{X}$ \\
\hline Intercâmbio temporário de pessoal & & & $\mathrm{X}$ & \\
\hline Incubadoras & & $\mathrm{X}$ & & \\
\hline Parques científicos e/ou tecnológicos & & & $\mathrm{X}$ & \\
\hline Empresa pertence a uma Universidade & & $\mathrm{X}$ & & \\
\hline Empresa é spin-off da Universidade & & $\mathrm{X}$ & & \\
\hline
\end{tabular}

NOTA: 1-sem importância; 2-pouco importante; 3-moderadamente importante; 4-muito importante.

FONTE: pesquisa de campo, 2009.

TABELA 12.PRINCIPAIS RAZÕES PARA COLABORAÇÃO DA DÍGITRO COM AS UNIVERSIDADES

\begin{tabular}{|c|c|c|c|c|}
\hline Razões da colaboração & $\mathbf{1}$ & 2 & 3 & 4 \\
\hline Transferência de tecnologia da Universidade & & & & $\mathrm{X}$ \\
\hline $\begin{array}{l}\text { Buscar conselhos de cunho tecnológico ou consultorias com pesqui- } \\
\text { sadores e/ou professores para solução de problemas relacionados à } \\
\text { produção }\end{array}$ & & & $\mathrm{X}$ & \\
\hline $\begin{array}{l}\text { Aumentar a habilidade da empresa para encontrar e absorver infor- } \\
\text { mações tecnológicas }\end{array}$ & & & $\mathrm{X}$ & \\
\hline $\begin{array}{l}\text { Conseguir informações sobre engenheiros ou cientistas e/ou tendên- } \\
\text { cias de P\&D nas áreas científicas }\end{array}$ & & & $\mathrm{X}$ & \\
\hline $\begin{array}{l}\text { Contratar pesquisas complementares, necessárias para as atividades } \\
\text { inovativas da empresa, em universidades e institutos, centros ou } \\
\text { laboratórios de pesquisa. }\end{array}$ & & & & $\mathrm{X}$ \\
\hline Contratar pesquisas que a empresa não pode realizar & & & $\mathrm{X}$ & \\
\hline $\begin{array}{l}\text { Fazer, o mais cedo possível, contatos com estudantes universitários } \\
\text { de excelência para futuro recrutamento }\end{array}$ & & & & $\mathrm{X}$ \\
\hline $\begin{array}{l}\text { Utilizar recursos disponíveis nas universidades e laboratórios de } \\
\text { pesquisa }\end{array}$ & & $\mathrm{X}$ & & \\
\hline Realizar testes necessários para produtos e processos da empresa & & & $\mathrm{X}$ & \\
\hline Receber ajuda no controle de qualidade & $\mathrm{X}$ & & & \\
\hline
\end{tabular}

NOTA: 1-sem importância; 2-pouco importante; 3-moderadamente importante; 4-muito importante.

FONTE: pesquisa de campo, 2009. 
